Supporting Information

\title{
Cationic versus Anionic Phthalocyanines for Photodynamic Therapy: What a Difference the Charge Makes.
}

Jan Kollar, $\uparrow$ Miloslav Machacek, $\neq$ Marie Halaskova, $\neq$ Juraj Lenco, $\S$ Radim Kucera, $\uparrow$ Jiri Demuth, $\uparrow$ Monika Rohlickova, $\neq$ Katerina Hasonova, $\neq$ Miroslav Miletin,$\uparrow$ Veronika Novakova, $\uparrow$ Petr Zimcik*,

${ }^{\dagger}$ Department of Pharmaceutical Chemistry and Pharmaceutical Analysis, Faculty of Pharmacy in Hradec Kralove, Charles University, Akademika Heyrovskeho 1203, Hradec Kralove, 500 05, Czech Republic

Department of Biochemical Sciences, Faculty of Pharmacy in Hradec Kralove, Charles University, Akademika Heyrovskeho 1203, Hradec Kralove, 500 05, Czech Republic ${ }^{\S}$ Department of Analytical Chemistry, Faculty of Pharmacy in Hradec Kralove, Charles University, Akademika Heyrovskeho 1203, Hradec Kralove, 500 05, Czech Republic zimcik@,faf.cuni.cz 


\section{Content}

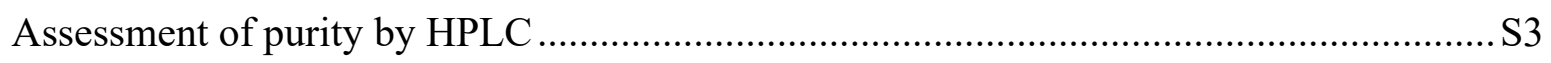

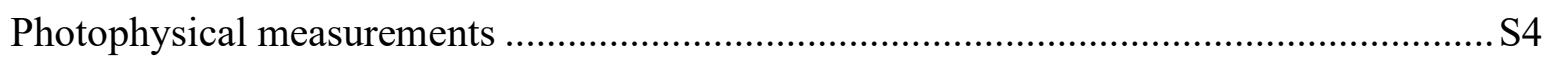

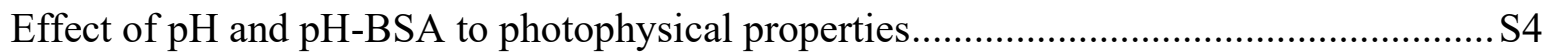

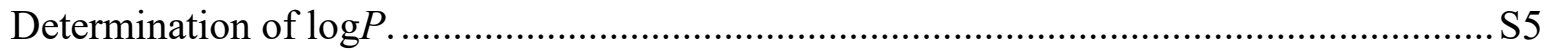

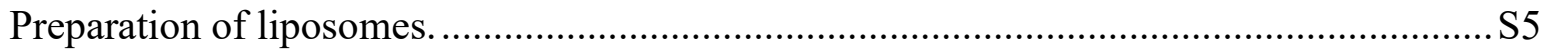

Determination of association constant with DOPC liposomes ....................................... S6

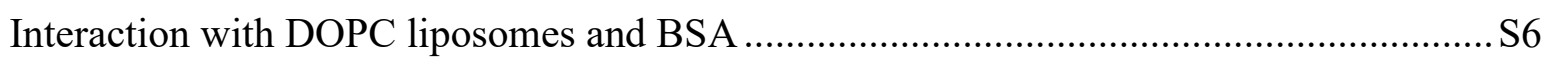

Determination of association constant with BSA ….................................................... S6

LC-MS analysis of bovine serum albumin interaction with singlet oxygen ......................S7

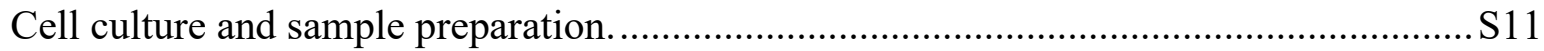

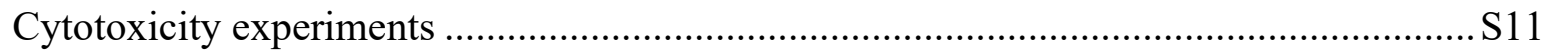

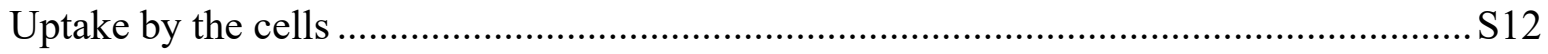

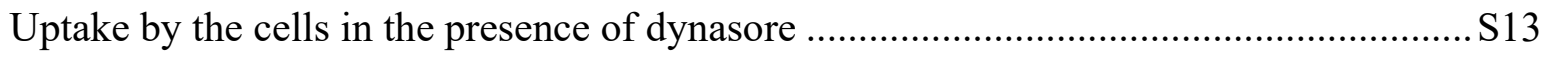

Subcellular localization and re-localization after irradiation ............................................ S14

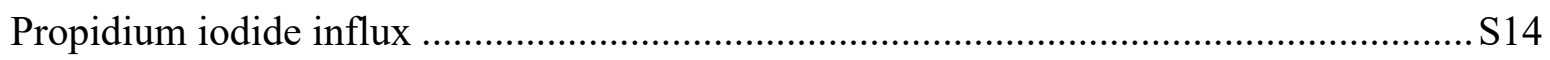

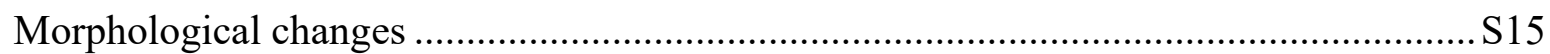

Literature data on photodynamic activity of phthalocyanines .......................................... S15

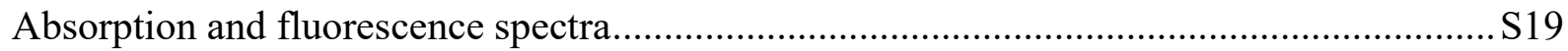

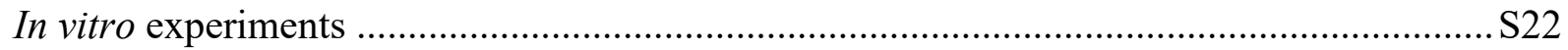

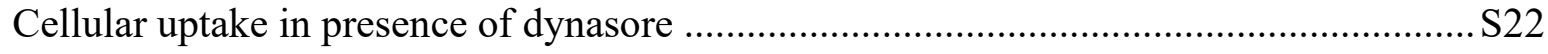

Assessment of photodynamic activity and dark toxicity ........................................... S22

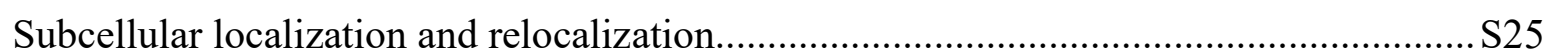

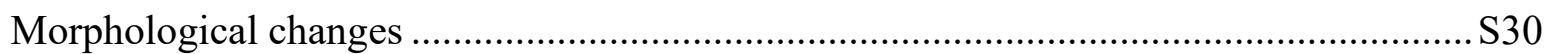

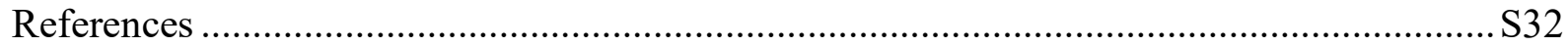




\section{Assessment of purity by HPLC}

Purity of the novel principal compounds $(2, \mathbf{3}, 7,8$ and 10) was evaluated by the LC 20A Prominence system (Shimadzu, Duisburg, Germany). The chromatograph consists of a DGU20A3 degasser, LC-20 AD pumps, an SIL-20AC autosampler, a CTO-20AC column oven, an SPD-M20A photodiode array detector, and a CBM-20AC communication module. The data were processed using LabSolutions software, version 5.85.

Anionic samples 2, 3, 7 and $\mathbf{8}$ were analyzed on a Hypersil BDS C18 column $(100 \times 4.6 \mathrm{~mm}$, particle size $2.4 \mathrm{~mm}$; ThermoFisher Scientific). The separation was performed using triethylamine as ion-pair agent. Due to the different number of carboxylic groups the hydrophobicity of the samples was considerably influenced. Thus, the $\mathbf{2}$ and $\mathbf{3}$ were analyzed using a mobile phase consisting of triethylamine acetate buffer $(50 \mathrm{mM}, \mathrm{pH} 6.3$, mobile phase A) and methanol (mobile phase B). The gradient time program was set as follows: 0-20 min $20 \rightarrow 40 \%$ B; $20-30 \min 40 \%$ B; 30-30.5 $\min 40 \rightarrow 20 \% \mathrm{~B}$, and the column was re-equilibrated for 4 min under the initial conditions. In case of compounds $\mathbf{7}$ and $\mathbf{8}$, methanol was replaced by acetonitrile and the gradient program was adapted as follows: $0-20 \min 20 \rightarrow 45 \%$ B; $20-25$ $\min 45 \% \mathrm{~B} ; 25-30 \min 45 \rightarrow 85 \% \mathrm{~B}, 30-35 \min 85 \% \mathrm{~B}, 35-36 \min 85 \rightarrow 20 \% \mathrm{~B}$ and the column was re-equilibrated for 4 min under the initial conditions. The column temperature was $40{ }^{\circ} \mathrm{C}$ and the flow rate was set at $0.75 \mathrm{~mL} \mathrm{~min}^{-1}$ for methanolic mobile phase and at $1 \mathrm{~mL} \mathrm{~min}^{-1}$ for mobile phase containing acetonitrile.

The chromatographic conditions for the separation of cationic $\mathbf{1 0}$ were altered. This compound was analyzed on a polybutadiene modified zirconia stationary phase $(150 \times 4.6 \mathrm{~mm}$; particle size $5 \mu \mathrm{m}$; ZirChrom Separations, Inc). The separation was accomplished under acidic conditions using mobile phase A - $25 \mathrm{mM}$ hydrochloric acid ( $\mathrm{pH} 2.1$ adjusted by Tris) and methanol as mobile phase B. Gradient elution was set as follows: $0-10 \mathrm{~min} 20 \% \mathrm{~B}$; $10-15 \mathrm{~min}$ $20 \rightarrow 65 \%$ B , $15-25 \min 65 \%$ B; $25-25.5 \min 65 \rightarrow 20 \%$ B and then the column was reequilibrated for 4 min under the initial conditions. The column temperature was set at $40{ }^{\circ} \mathrm{C}$ and the flow rate was $0.5 \mathrm{~mL} \cdot \mathrm{min}^{-1}$.

All compounds were analyzed by a diode array detector and the chromatograms (Figure S1) were recorded at wavelengths corresponding to the absorption maxima of the individual sample $(2-697 \mathrm{~nm} ; 3$ and $7-677 \mathrm{~nm} ; 8-673 \mathrm{~nm} ; \mathbf{1 0}-690 \mathrm{~nm})$. The purity was in all cases $>96 \%$. 
a)
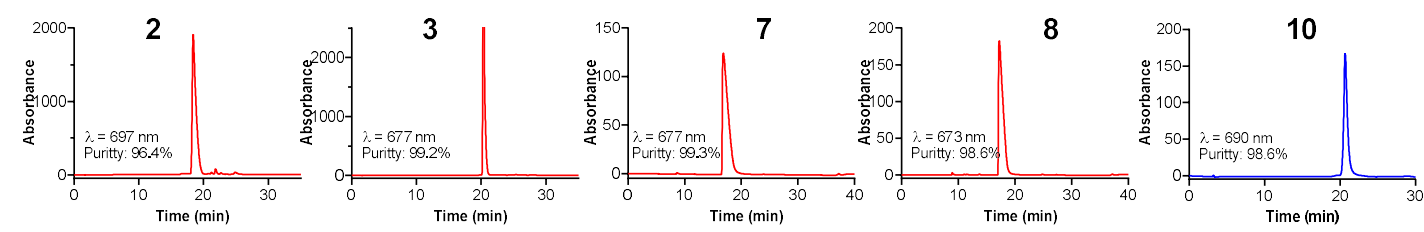

b)
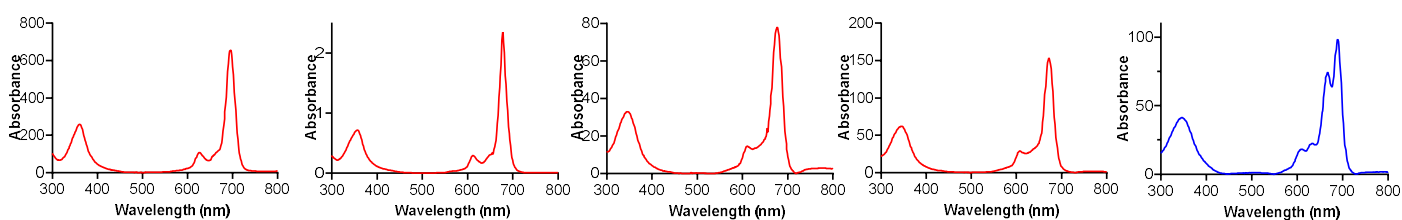

Figure S1. a) HPLC chromatograms of new compounds used for assessment of purity. b) Absorption spectra at the maximum of the chromatographic peak.

\section{Photophysical measurements}

The singlet oxygen quantum yields $\left(\Phi_{\Delta}\right)$ and the fluorescence quantum yields $\left(\Phi_{\mathrm{F}}\right)$ of tested samples in DMF and phosphate-buffered saline (PBS) were determined using published comparative methods with unsubstituted ZnPc (obtained from Sigma-Aldrich) as a reference compound. ${ }^{1}$ The following values for $\mathrm{ZnPc}$ were used in the calculations: $\Phi_{\mathrm{F}}=0.32(\mathrm{THF})^{2}$, $\Phi_{\Delta}=0.56(\mathrm{DMF})^{3}$.

\section{Effect of $\mathrm{pH}$ and $\mathrm{pH}-\mathrm{BSA}$ to photophysical properties}

Spectral and photophysical data for all Pcs 1-10 at different $\mathrm{pH}$ were determined using BrittonRobinson (BR) buffer $\left(0.04 \mathrm{M} \mathrm{H}_{3} \mathrm{BO}_{3}, 0.04 \mathrm{M} \mathrm{H}_{3} \mathrm{PO}_{4}\right.$ and $0.04 \mathrm{M} \mathrm{CH}_{3} \mathrm{COOH}$ adjusted to selected $\mathrm{pH}$ (4-11) by $0.2 \mathrm{M} \mathrm{NaOH}$ ) with ionic strength adjusted with $\mathrm{NaCl}$ to $\mathrm{I}=0.15 \mathrm{M}$. The $\mathrm{pH}$ of the buffer was determined using $\mathrm{pH} 8+$ DHS $\mathrm{pH}$ meter (XS instruments) that was calibrated with a three-point calibration at $\mathrm{pH}$ 4.00, 7.00, 10.00 before measurements. Stock solution of Pcs 1-10 $(25 \mu \mathrm{M})$ were prepared in BR buffer of $\mathrm{pH}$ 6.0. In case of poorly water soluble 9 and 10, the solution was prepared from DMSO stock solution (10 mM). Then, typically $2.0 \mathrm{~mL}$ of the selected buffer and $80 \mu \mathrm{L}$ of stock solution of Pc 1-10 was added to the cuvette (final concentration of Pcs was $1 \mu \mathrm{M}$ ) and the absorption and fluorescence spectra $\lambda_{\mathrm{ex}}=595 \mathrm{~nm}$ for compound $\mathbf{1}, \lambda_{\mathrm{ex}}=610 \mathrm{~nm}$ for compounds $\mathbf{2 - 1 0}$ were recorded. In case when the effect of $\mathrm{pH}$ on the solution with bovine serum albumin (BSA) was investigated, the Pc 
stock solution was charged with BSA $(500 \mu \mathrm{M})$ with the final BSA concentration after dilution in the cuvette being $20 \mu \mathrm{M}$.

\section{Determination of $\log P$.}

Stock solutions of studied Pcs were prepared at concentration of $100 \mu \mathrm{M}$ in DMF $(\mathbf{4 , 9 , 1 0})$ or in water $(1-3,7,8)$. For cationic Pcs 4, 9 and 10, mixture of PBS $(400 \mu \mathrm{L})$ and $n$-octanol $(400 \mu \mathrm{L})$ was prepared into plastic vial and $20 \mu \mathrm{L}$ of the DMF stock solution of Pcs was added. For anionic 1-3, 7 and 8, mixture of PBS buffer $(380 \mu \mathrm{L})$ and $n$-octanol $(400 \mu \mathrm{L})$ and DMF $(20$ $\mu \mathrm{L}$ ) was prepared into plastic vial and $20 \mu \mathrm{L}$ of the water stock solution of Pcs was added. The mixture was vortexed for $5 \mathrm{~min}$ at $\mathrm{rt}$ and then centrifuged (10 $000 \mathrm{rpm}, 10 \mathrm{~min}, \mathrm{rt})$. The octanol and water phases were separated (the middle part between the layers was discarded) and $20 \mu \mathrm{L}$ of each layer was diluted into DMF $(2 \mathrm{~mL})$. Emission spectra $\left(\lambda_{\mathrm{exc}}=360 \mathrm{~nm}\right)$ of these DMF solutions were measured and the $\log P$ was calculated: $\log P=\log \left(\mathrm{F}_{\mathrm{OctOH}} / \mathrm{F}_{\mathrm{PBS}}\right)$, where $\mathrm{F}_{\mathrm{OctOH}}$ and $\mathrm{F}_{\mathrm{PBS}}$ are integrated emission spectra of the DMF solution for the $n$-octanol and water layers, respectively.

\section{Preparation of liposomes.}

Dioleoylphostphatidylcholine (DOPC, Lipoid, Germany) (39.3 mg, $50 \mu \mathrm{mol})$ were dissolved in chloroform and evaporated in a $100 \mathrm{~mL}$ round-bottom flask on water bath with temperature set at $37^{\circ} \mathrm{C}$. The thin lipid film was further left on the bath for $30 \mathrm{~min}$ at a pressure of $5 \mathrm{mbar}$ to remove all trace of organic solvent. After that, PBS buffer $(2 \mathrm{~mL})$ was added and lipids were removed from the flask walls by gentle hand shaking. The suspension was then vortexed for 5 min to form multilamellar vesicles and left to stand for $24 \mathrm{~h}$ at room temperature to allow complete swelling. Large unilamellar vesicles were formed by extrusion using small hand extruder LiposoFast Basic (Avestin, Canada). The suspension was passed forth and back 21 times through two stacked polycarbonate filters (pore diameter $100 \mathrm{~nm}$ ) at room temperature. In this way prepared stock solution of DOPC liposomes had concentration of $25 \mathrm{mM}$. The liposomes were characterized by the photon correlation spectroscope Zetasizer Nano-ZS (Malvern, UK) after dilution to $1 \mathrm{mM}$ : Z-average size: $127.7 \pm 1.32 \mathrm{~nm}$, polydispersity index $=$ $0.075 \pm 0.020$ (average from 3 determinations, see below) 


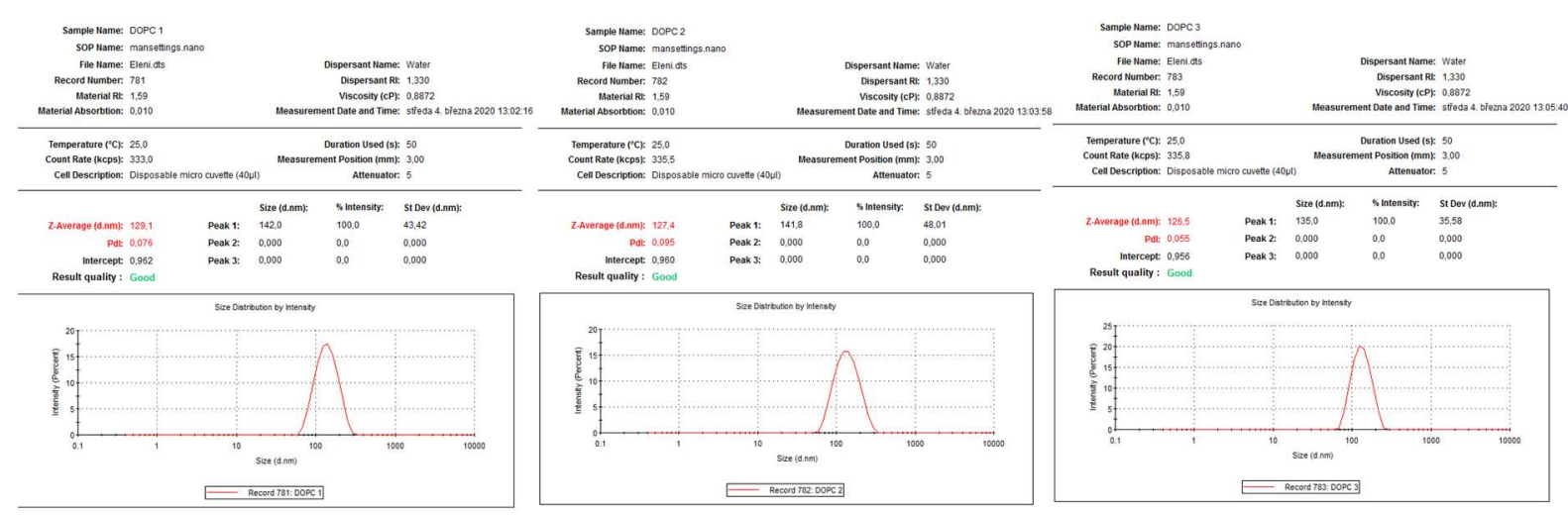

\section{Determination of association constant with DOPC liposomes}

A solution all of Pcs 1-10 $(2 \mathrm{~mL}, 1 \mu \mathrm{M})$ in PBS buffer was prepared in quartz cuvette. In case of 9 and 10, a stock solution in DMSO $(10 \mathrm{mM})$ was diluted to PBS to the final concentration of $1 \mu \mathrm{M}$. Subsequently, small volumes (typically 2-10 $\mu \mathrm{L}$ ) of DOPC liposome stock solution $(25 \mathrm{mM})$ in PBS buffer were added, the solution was stirred for few seconds and the absorption and emission spectra ( $\lambda_{\mathrm{exc}}=350 \mathrm{~nm}, 350 \mathrm{~nm}, 335 \mathrm{~nm}$ and $370 \mathrm{~nm}$ for 7-10, respectively) were collected. The binding constatnt, $K_{\mathrm{L}}$, was determined by nonlinear regression (Prism 8 for Windows, GraphPad Software) from the plot of dependence of the bound fraction against concentration of lipids. The bound fraction was calculated from the emission intensity ( $F$ $\left.F_{\min }\right) /\left(F_{\max }-F_{\min }\right)$ where $\mathrm{F}$ is fluorescence intensity at given concentration, $F_{\min }$ is fluorescence without any lipids, $F_{\max }$ is fluorescence intensity at full saturation. $F_{\min }$ was equal zero for strongly aggregated compounds $\mathbf{7 , 8}$ and $\mathbf{1 0}$ that had no fluorescence in PBS.

\section{Interaction with DOPC liposomes and BSA}

A solution of Pcs 7-10 $(2 \mathrm{~mL}, 1 \mu \mathrm{M})$ in PBS buffer was prepared in quartz cuvette and DOPC liposomes stock solution $(25 \mathrm{mM})$ was added $(100 \mu \mathrm{L}$; final concentration of lipids $1.2 \mathrm{mM})$, the solution was stirred for few seconds and the absorption and emission spectra were collected. Subsequently, BSA in PBS was added (final concentration $35 \mu \mathrm{M}$ ) and absorption spectra and emission spectra were collected. In a reverse experiment, BSA in PBS was added first (final concentration $35 \mu \mathrm{M}$ ) followed by addition of DOPC liposomes (final concentration of lipids $1.2 \mathrm{mM})$.

\section{Determination of association constant with BSA}

A solution of Pcs 1-10 $(2.5 \mathrm{~mL}, 1 \mu \mathrm{M})$ in PBS buffer was prepared in quartz cuvette. Subsequently, small volumes of BSA stock solution in PBS buffer ( 2 mg BSA in $1 \mathrm{ml}$ PBS or 
$30 \mathrm{mg}$ BSA in $1 \mathrm{ml}$ PBS) were added, the solution was stirred for few seconds and the absorption and emission spectra were collected (for excitation wavelengths see below). The association constant, $K_{\mathrm{b}}$, was determined by nonlinear regression (Prism 8 for Windows, GraphPad Software) from the plot of dependence of the bound fraction against concentration of BSA. The bound fraction was calculated from the change of the absorbance $(\Delta A)$ at Q-band at wavelength with the maximum change in absorbance (see below "monitoring wavelength). No change in absorption spectra was detected for 4-6 suggesting no or very limited interaction. Emission spectra were used for determination of $\Phi_{\mathrm{F}}$ and for assessment of possible quenching of the excited states by BSA.

\begin{tabular}{lll}
\hline Compound & $\lambda_{\text {exc }}$ & Monitoring wavelength \\
\hline $\mathbf{1}$ & 607 & 647 \\
$\mathbf{2}$ & 635 & 694 \\
$\mathbf{3}$ & 618 & 676 \\
$\mathbf{7}$ & 612 & 676 \\
$\mathbf{8}$ & 612 & 680 \\
$\mathbf{9}$ & 605 & 635 \\
$\mathbf{1 0}$ & 605 & 635 \\
\hline
\end{tabular}

\section{LC-MS analysis of bovine serum albumin interaction with singlet oxygen}

Stock solution of BSA in PBS $(2 \mathrm{~mL}, 1 \mathrm{mg} / \mathrm{mL}, 15 \mu \mathrm{M})$ was mixed with stock solution 3 or 4 in PBS (final concentration in the sample $5 \mu \mathrm{M}$ ). The solution was split into half and 1 $\mathrm{mL}$ was irradiated on Petri dishes in the similar conditions as for phototoxicity studies $(\lambda>570$ $\left.\mathrm{nm}, 12.4 \mathrm{~mW} \mathrm{~cm}{ }^{-2}, 15 \mathrm{~min}, 11.2 \mathrm{~J} \mathrm{~cm}^{-2}\right)$. The second half $(1 \mathrm{~mL})$ was kept strictly in the dark and used as the control without irradiation. BSA in PBS $(1 \mathrm{mg} / \mathrm{mL}, 15 \mu \mathrm{M})$ alone, either irradiated $(1 \mathrm{~mL})$ or not $(1 \mathrm{~mL})$, was used as a second control. All solutions were prepared $\mathrm{ad}$ hoc in dark room in the absence of light. The experiment was performed in quadruplicate.

Unless otherwise indicated, chemicals and reagents were purchased from SigmaAldrich/Merck in the highest available. grade. LC-MS-grade solvents and additives to mobile phases for LC-MS analyses were obtained from Merck or Honeywell. Immediately after irradiation, BSA from $100 \mu$ of each sample was purified via gel filtration using Zeba spin desalting columns with molecular weight cut-off of $7 \mathrm{kDa}$ (Thermo Fisher Scientific). Samples were buffered by adding $5 \mu \mathrm{l}$ of $1 \mathrm{M}$ Tris- $\mathrm{HCl} \mathrm{pH} 7.5$, and disulfide bridges in BSA were reduced in $5 \mathrm{mM}$ tris(2-carboxyethyl)phosphine at $37^{\circ} \mathrm{C}$ for $60 \mathrm{~min}$. SOLu-trypsin was added 
in 1:50 weight ratio, and BSA was digested at $37^{\circ} \mathrm{C}$ overnight. Next day, reduction reaction was repeated, and free thiol groups were thiomethylated in $20 \mathrm{mM} S$-methyl methanethiosulfonate at room temperature for $30 \mathrm{~min}$.

LC-MS analyses were carried out using a Vanquish Horizon UHPLC system hyphenated to a Q Exactive HF-X mass spectrometer (Thermo Fisher Scientific). Mobile phase A and B was water and acetonitrile, respectively, both acidified with $0.1 \%$ formic acid. Peptides from $5 \mu$ of each sample were separated using an Acquity UPLC, $1.7 \mu \mathrm{m} \mathrm{CSH} \mathrm{C} 18,130 \AA, 2.1$ $\times 150 \mathrm{~mm}$ column (Waters) using a gradient from 1 to $34 \%$ mobile phase B in $23 \mathrm{~min}$ at a flow rate of $250 \mu \mathrm{L} / \mathrm{min}$ and a column temperature of $60{ }^{\circ} \mathrm{C}$. Before the gradient started, the flow downstream the column was diverted to waste, and unretained compounds were washed out at $1 \%$ mobile phase B isocratically for $2 \mathrm{~min}$. Eluted peptides were introduced into the mass spectrometer via electrospray ionization at $3 \mathrm{kV}$. MS spectra were acquired within $\mathrm{m} / z$ 325-2 000 with a $3 \times 10^{6}$ target charges in the orbitrap at 60000 resolution and with a maximum ion time of $100 \mathrm{~ms}$. The three most intense precursors with $\geq 2$ and $\leq 5$ charges and a threshold intensity of $2.5 \times 10^{5}$ were selected for higher energy collisional dissociation that was triggered close to the chromatographic peak apex. Only the most intense charge state for each peptide was subjected to dissociation with an exclusion time of $10 \mathrm{~s}$. An isolation window of $2.6 \mathrm{~m} / \mathrm{z}$ offset by $0.3 \mathrm{~m} / \mathrm{z}$ and a normalized collision energy of 27 were used. MS/MS spectra were acquired at a resolution of 15000 with a $2 \times 10^{5}$ target charges in the orbitrap and a maximum ion time of $200 \mathrm{~ms}$. All experiments were run in duplicate.

The LC-MS data were assigned to tryptic peptides from a sequence of processed BSA in Proteome Discoverer ver. 2.3 (Thermo Fisher Scientific) using integrated Byonic ver. 3.5. search engine (Protein Metrics). A full-tryptic cleavage was used with a maximum of one missed cleavage allowed. The mass tolerance was set at $10 \mathrm{ppm}$ for precursors and at $20 \mathrm{ppm}$ for fragments. To detect and quantify oxidative changes to BSA induced by irradiated Pcs 3 and 4, previously described modifications initiated by singlet oxygen were considered as dynamic modifications: His +14 , His +16 , His +32 , Met +16 , Met +32 , Cys +32 , Cys +48 , $\operatorname{Trp}+16$, Trp +32 and Tyr +16 (see below). No modification in Tyr was found. Peptides identified with a Byonic score $\geq 200$ together with the chromatographic peak area of their precursors were exported to Prism for Windows ver. 8.4.0 (GraphPad software) for statistical analysis (Figure S2). 

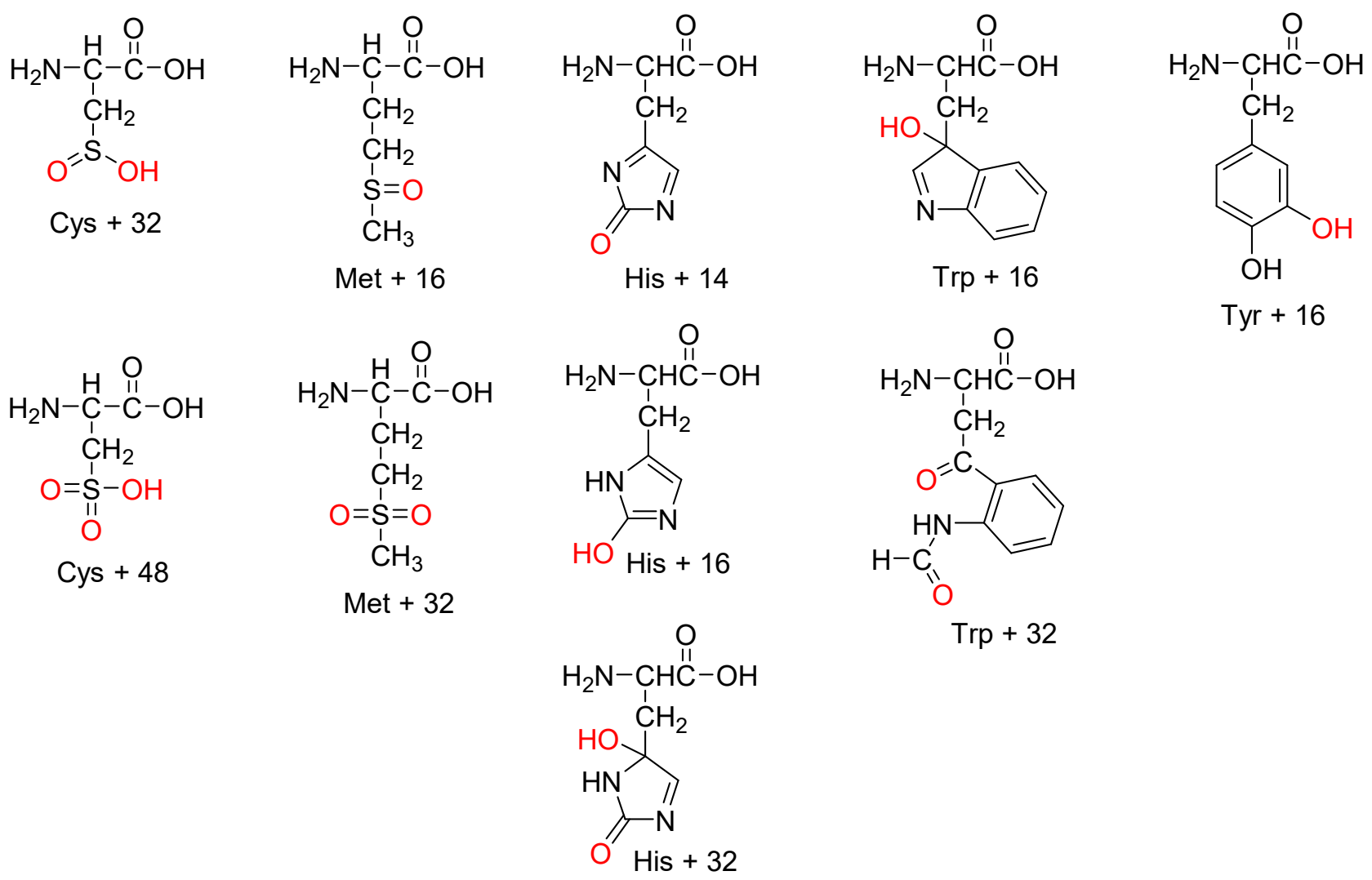

$$
\text { Trp }+32
$$



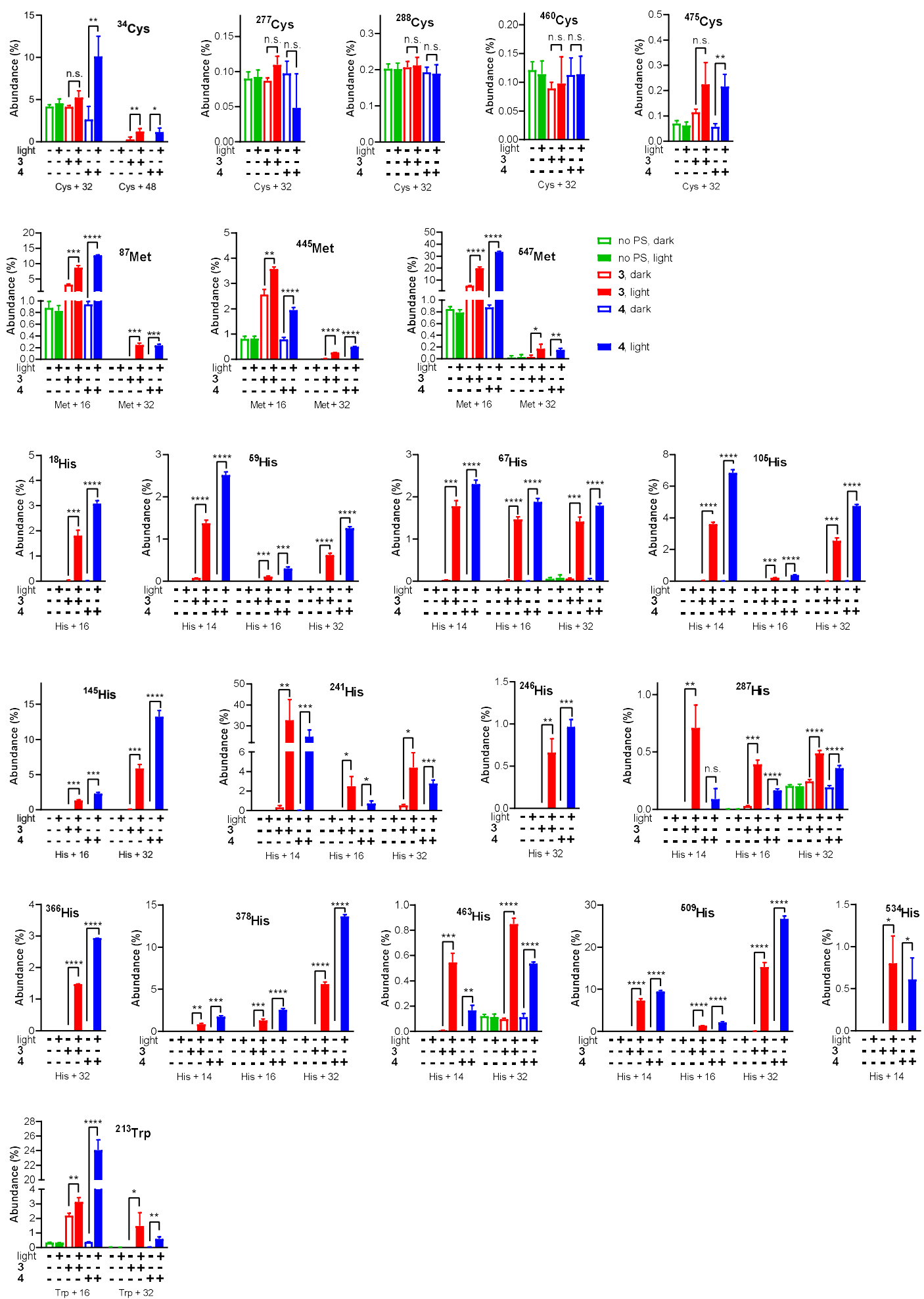

Figures S2. Results of the oxidative modification of Cys, Met, His and Trp in BSA upon photodynamic treatment with Pc 3 (red) or 4 (blue) or untreated (green). The irradiated samples are drawn as full columns, not irradiated as blank columns. Four independent experiments were performed and analyzed by Welch's t-test. n.s., $p>0.05 ;^{*}, \mathrm{p}<0.05 ;{ }^{* *}, \mathrm{p}<0.01 ; * * *, \mathrm{p}<$ $0.001 ; * * * *, p<0.0001$. 


\section{Cell culture and sample preparation.}

The human cervical carcinoma (HeLa), human colorectal carcinoma (HCT 116) and human breast adenocarcinoma (MCF-7) cell lines were purchased from the American Type Cell Culture Collection (ATCC; United States). The cells were cultured in Dulbecco's modified Eagle's medium (DMEM) without phenol red (Lonza, Belgium) and supplemented with 10\% heat-inactivated fetal bovine serum (Sigma), 1\% penicillin/streptomycin solution (Lonza), 10 mM HEPES buffer (Sigma), and $4 \mathrm{mM}$ ultraglutamine I (alanyl-L-glutamine; Lonza). This serum-containing medium (SCM) is further referred to as the cell culture medium. The cell lines were cultured in $75 \mathrm{~cm}^{2}$ tissue culture flasks (TPP, Switzerland) and maintained in a $\mathrm{CO}_{2}$ incubator at $37{ }^{\circ} \mathrm{C}$ in a humidified atmosphere of $5 \% \mathrm{CO}_{2}$ and subcultured every $3-4$ days. For the cytotoxicity experiments (phototoxicity and dark toxicity), cells were seeded into 96-well plates (TPP) at a density of $7.5 \times 10^{3}\left(\mathrm{HeLa}\right.$ and MCF-7) or $1.0 \times 10^{4}$ (HCT 116) cells per well for $24 \mathrm{~h}$.

Stock solutions of the investigated compounds were prepared in the medium (either in SCM or in serum-free medium (SFM) for different experiments) at a concentration of $1.0 \mathrm{mM}$ (for Pcs 2, 4, 5, 7 and 8), $1.5 \mathrm{mM}$ (for Pcs 1, 3 and 6) or 2.5 mM (for $\mathrm{S}_{3} \mathrm{AlOHPc}$ ) or in DMSO at a concentration of $10 \mathrm{mM}$ (Pcs 9 and 10) and were sterilized by filtration through $0.22 \mu \mathrm{m}$ syringe MCE filters. No measurable change in concentration was detected after passage through the filter based on the absorption spectra measured before and after filtration.

\section{Cytotoxicity experiments}

Dark toxicities (inherent toxicities of the studied photosensitizers (PSs) in the absence of any light) were assayed over a wide concentration range after $24 \mathrm{~h}$ incubation with HeLa cells. Cell viability was determined using the Neutral Red (NR, Sigma) uptake assay based on the ability of the living cells to incorporate NR into their intact lysosomes. The soluble NR was measured as its optical density at $\lambda=540 \mathrm{~nm}$ using a Tecan Infinite $200 \mathrm{M}$ plate reader (Tecan, Austria). The viability of each experimental group was expressed as the percentage of the untreated controls incubated under the same conditions (100\%). After NR staining of the cells (before lysis), the cells were briefly investigated under an inverted microscope to verify qualitative changes in cellular morphology and NR uptake into intact lysosomes. These observations were in accordance with subsequent quantitative measurements. False positivity in absorbance measurements using the NR uptake assay method was also eliminated. No absorbance interference of any PS with NR over the entire concentration scale (PDT and dark toxicity experiments) was observed. 
For the photodynamic treatment experiments (phototoxicity), HeLa, MCF-7, HCT 116 cells were incubated with various concentrations of the studied compounds for $12 \mathrm{~h}$. The cells were then washed with prewarmed serum-free cell culture medium, fresh cell culture medium was added, and the cells were irradiated for 15 min using a $450 \mathrm{~W}$ ozone-free Xe lamp (Newport) with its intensity reduced to $400 \mathrm{~W}$ that was equipped with a long-pass filter (Newport OG570) and an $8-\mathrm{cm}$ water filter to cut off undesirable wavelengths and heat radiation $(\lambda>570 \mathrm{~nm}, 12.4$ $\mathrm{mW} \mathrm{cm}{ }^{-2}, 15 \mathrm{~min}, 11.2 \mathrm{~J} \mathrm{~cm}^{-2}$ ). Cellular viability was measured after an additional $24 \mathrm{~h}$ by NR as previously described. At least five independent experiments, each in triplicate, were performed.

The concentrations of the tested compounds that induced a $50 \%$ viability decrease after treatment under the dark conditions $\left(\mathrm{TC}_{50}\right.$, the median toxic concentration) or after the photodynamic treatment ( $\mathrm{EC}_{50}$, the median effective concentration) were calculated using GraphPad Prism software (version 8.0.1; GraphPad Software, Inc., San Diego, CA, USA) for each independent experiment. The data are presented as the means \pm standard deviation of these values.

\section{Uptake by the cells}

HeLa cells were seeded into $6 \mathrm{~cm}$ Petri dishes (TPP) at a density of $5.0 \times 10^{5}$ cells per dish. The cells were left to grow for $24 \mathrm{~h}$, the medium was removed, and $5 \mathrm{~mL}$ of a $4 \mu \mathrm{M}$ solution of 1-10 in SCM were added. The cells were washed two times with $5 \mathrm{~mL}$ of prewarmed (PBS; Sigma) after $0.002,0.5,1,2,4,6,8$ and $12 \mathrm{~h}$. Fresh SFM (10 mL) was added, and the cells were scraped and transferred to $15 \mathrm{~mL}$ centrifugation tubes (TPP) and centrifuged for $5 \mathrm{~min}$ at $70 \times \mathrm{g}$. The supernatant was replaced with $2 \mathrm{~mL}$ of PBS, and the pellet was gently resuspended and centrifuged again. After the last centrifugation, the supernatant was replaced with $500 \mu \mathrm{L}$ of MQ-water (Millipore, USA) (for 1-8 and S3AIOHPc) or with $500 \mu \mathrm{L}$ of DMSO (for 9 and 10). Lysis of the cells was performed overnight at $-80^{\circ} \mathrm{C}$. The samples were quickly thawed at $37^{\circ} \mathrm{C}$ and frozen at $-80{ }^{\circ} \mathrm{C}$ for an additional $2 \mathrm{~h}$. The fluorescence of the samples was measured after addition of 2 vol.\% of supplements to ensure monomeric states of PSs using an FS5 spectrofluorimeter and was plotted against the incubation time. Excitation and emission wavelengths as well as supplements are listed in Table S1. Nonspecific fluorescence was excluded by the control experiments free of PSs. A calibration curve was constructed using dilutions of the dye stock solution into the cell lysate prepared as described above (i.e., in water or in DMSO). The uptake experiments were performed in duplicate. Experiments were performed in dark the entire time. 
The amounts of protein in the samples were assessed using the BCA (bicinchoninic acid) method. A calibration curve was created using BSA dissolved in MQ-water at concentrations of $0,50,100,200,400,600,800$ and $1000 \mu \mathrm{g} / \mathrm{mL}$. A working solution of BCA $(4 \%$ $\mathrm{CuSO}_{4} \cdot 6 \mathrm{H}_{2} \mathrm{O}$ mixed ad hoc with BSA stock solution at a 1:50 ratio) was added to $10 \mu \mathrm{L}$ of the samples. Absorbance $(562 \mathrm{~nm})$ was measured after $30 \mathrm{~min}$ incubation at $37{ }^{\circ} \mathrm{C}$ using a Tecan Infinite M 200 plate reader.

Table S1. Parameters used to monitor uptake of PSs to HeLa cells and type of supplement added to facilitate monomeric state of PSs.

\begin{tabular}{cccl}
\hline Compound & $\lambda_{\text {exc }}$ & $\lambda_{\text {emi }}$ & Supplementation \\
\hline $\mathbf{1}$ & 375 & 663 & $1 \mathrm{M} \mathrm{NaOH}$ \\
$\mathbf{2}$ & 361 & 710 & $1 \mathrm{M} \mathrm{NaOH}$ \\
$\mathbf{3}$ & 361 & 693 & $1 \mathrm{M} \mathrm{NaOH}$ \\
$\mathbf{4}$ & 360 & 691 & $1 \mathrm{M} \mathrm{HCl}$ \\
$\mathbf{5}$ & 620 & 690 & $1 \mathrm{M} \mathrm{HCl}$ \\
& 630 & 726 & $1 \mathrm{M} \mathrm{HCl}$ \\
& & & \\
$\mathbf{7}$ & 352 & 690 & $10 \% \mathrm{Triton}-\mathrm{X} 100$ \\
$\mathbf{8}$ & 352 & 684 & $10 \% \mathrm{Triton}-\mathrm{X} 100$ \\
$\mathbf{9}$ & 608 & 684 & - \\
$\mathbf{1 0}$ & 613 & 698 & - \\
S3AlOHPc & 608 & 675 & $1 \mathrm{M} \mathrm{NaOH}$ \\
\hline
\end{tabular}

\section{Uptake by the cells in the presence of dynasore}

HeLa cells were seeded onto 96-well plates at concentration 75000 cells $/ \mathrm{ml}$ and incubated $24 \mathrm{~h}$ prior to addition of inhibitor. Cells were pretreated with different concentrations of inhibitor (50 $\mu \mathrm{M}, 80 \mu \mathrm{M}$ and $100 \mu \mathrm{M}$ ) for $1 \mathrm{~h}$. Dynasore was used at concentrations which provided inhibition of uptake with low cytotoxicity and which were previously used in other studies. ${ }^{4,5}$ Following $1 \mathrm{~h}$ preincubation time tested Pcs were added and cells were incubated for next $4 \mathrm{~h}$ in the presence of the inhibitor. After the end of incubation period cells were washed 3 times with PBS prior to lysis by 5\% Triton X-100 (cpd. 2, 5, 8) or by DMSO (10). Finally, fluorescence was measured using Tecan Infinite M200 $\left(\lambda_{\mathrm{exc}}=360 \mathrm{~nm}\right)$ and emission was monitored at $\lambda_{\mathrm{em}}=713$ (cpd. 2), 693 (cpd. 5), 685 (cpd. 8) and $700 \mathrm{~nm}$ (cpd. 10) and results were compared to control group incubated with Pcs at the same conditions but in the absence of the inhibitor. All experiments were performed in triplicate. To exclude the interference with 
endogenous chromophores, the cells incubated at the same conditions without any inhibitor or Pc were also measured.

\section{Subcellular localization and re-localization after irradiation}

HeLa cells were seeded on Petri dishes suitable for confocal microscopy (WilCo Wells, Netherlands) at the density of $7.5 \times 10^{4}$ cells per dish. Incubation with PSs in SCM ( $\left.4 \mu \mathrm{M}, 2 \mathrm{~mL}\right)$ was performed for $12 \mathrm{~h}$ in an incubator at $37{ }^{\circ} \mathrm{C}$ with constant humidity and $5 \% \mathrm{CO}_{2}$ atmosphere. Medium was removed, cells were washed twice with prewarmed PBS and fresh SFM containing A) $0.4 \mu \mathrm{M}$ MitoTracker ${ }^{\mathrm{TM}}$ Green FM (Molecular Probes, Thermo Fisher Scientific, USA; further referred as "MitoTracker") and $0.4 \mu \mathrm{M}$ LysoTrackerTM Blue DND-22 (Molecular Probes; further referred as "LysoTracker") or B) 10 nM Hoechst 33342 (Molecular Probes; further referred as "Hoechst") and 1× CellMask"TM Green Plasma Membrane Stain (Molecular Probes; further referred as "CellMask") was added for $20 \mathrm{~min}$ (A) and $10 \mathrm{~min}$ (B). Cells were washed twice with PBS, fresh SFM was added and samples were placed in a stagetop $\mathrm{CO}_{2}$ incubator (Okolab, Italy) and examined with Nikon Ti-E microscope (Nikon, Japan) and $60 \times$ oil immersion objective lens. Microphotographs were taken with Andor Zyla 5.5 sCMOS camera (Andor Technology, United Kingdom) using FITC, DAPI and Cy5 filter sets for MitoTracker, LysoTracker and PSs, respectively. The same field of view was subsequently taken after 5 min of irradiation (microscope pE-300 CoolLED fluorescence source (CoolLED, United Kingdom) and Cy5 filter set on its lowest power setting $(1 \%)-\lambda=604-644 \mathrm{~nm}$, $84.5 \mathrm{~mW} \mathrm{~cm} \mathrm{~cm}^{-2}, 5 \mathrm{~min}, 25.3 \mathrm{~J} \mathrm{~cm}^{-2}$ ) for monitoring of re-localization of PSs within the cells. Similar technique was used to acquire video of real-time re-localization of $\mathbf{2}$ and $\mathbf{6}$. Imaging was performed using Cy5 fluorescence channel and 40× dry objective lens. Fluorescence source was set at $50 \%$ of its power and acquisition of video (and therefore also duration of irradiation) was performed for $1.5 \mathrm{~min}\left(\lambda=604-644 \mathrm{~nm}, 1203.4 \mathrm{~mW} \mathrm{~cm}{ }^{-2}, 1.5 \mathrm{~min}, 108.3 \mathrm{~J} \mathrm{~cm}^{-2}\right)$ using $2 \times 2$ binning. Video file was speeded up six times for better perception of changes.

\section{Propidium iodide influx}

To follow changes of propidium iodide (PI) influx, subsequent nuclei staining and therefore damage to membranes (PI is unable to cross intact biological membranes), HeLa cells were seeded and incubated with PSs as described above in section "Subcellular localization and re-localization after irradiation." Cells were washed twice with pre-warmed PBS and fresh SFM containing $10 \mathrm{nM}$ Hoechst (Molecular Probes) and 1.5 $\mu \mathrm{M}$ PI (Molecular Probes) was added for 15 min. Cells were washed and SFM containing 1.5 $\mu$ M PI (Molecular Probes) was added. Samples were transferred to a stage-top $\mathrm{CO}_{2}$ incubator and examined with microscope using 
$60 \times$ oil immersion objective lens together with DAPI and Cy3 fluorescence channels for Hoechst and PI, respectively. Images were acquired before irradiation, 5, 10 and 15 min during irradiation and 5, 15 and $45 \mathrm{~min}$ after irradiation. Irradiation was performed using microscope fluorescence source set on lowest power $\left(\lambda=604-644 \mathrm{~nm}, 84.5 \mathrm{~mW} \mathrm{~cm}^{-2}, 15 \mathrm{~min}, 76.0 \mathrm{~J} \mathrm{~cm}^{-}\right.$ 2).

\section{Morphological changes}

HeLa cells were seeded on 4-well cover glass chambered slides (Eppendorf, Germany) at the density of $2.0 \times 10^{4}$ cells per well and left to grow for $24 \mathrm{~h}$ prior to addition of PSs. Incubation with PSs (at the concentrations corresponding to their $\mathrm{EC}_{15}$ or $\mathrm{EC}_{85}$ ) was performed for $12 \mathrm{~h}$. Irradiation was performed the same way as in phototoxicity studies (see section "Cytotoxicity experiments"). After $24 \mathrm{~h}$, the cells were stained for $15 \mathrm{~min}$ with $0.4 \mu \mathrm{M}$ MitoTracker ${ }^{\mathrm{TM}}$ Red CMXRos (Molecular Probes), washed twice and further incubated for $5 \mathrm{~min}$ in fresh SFM to remove unbound probe. Fixation of the specimens was done using prewarmed $4 \%$ paraformaldehyde dissolved in SCM for $15 \mathrm{~min}$ at $37^{\circ} \mathrm{C}$. Cells were rinsed three times for 5 min with PBS $(\mathrm{pH}=7.4)$ and permeabilized using 0.5\% Triton X-100 (Sigma) for 15 min at room temperature. Cells were washed three times for 5 min with PBS and blocked 60 min at room temperature with 3\% bovine serum albumin (BSA, MP Biomedicals, USA) in PBS. Incubation with $5 \mathrm{U} / \mathrm{mL}$ of Alexa Fluor 488 phalloidin (Molecular Probes) in 3\% BSA was performed for $30 \mathrm{~min}$. Specimens were rinsed and stained with $10 \mathrm{nM}$ Hoechst in PBS for 15 min and subsequently rinsed again and washed 5 min with MQ-water to remove excess salts. Mounting was performed after drying using ProLong Gold antifade mountant (Molecular Probes) overnight. Photomicrographs were taken using Nikon A1+ confocal system and 60× oil immersion objective lens. 6 - 14 confocal planes were taken to cover whole volume of specimens using 405, 488, and $561 \mathrm{~nm}$ lasers for DAPI, FITC and Cy3.5 fluorescence channels. Pinhole was set up at $26.8 \mu \mathrm{m}$.

\section{Literature data on photodynamic activity of phthalocyanines}

Table S2. Photodynamic activity of water soluble anionic and cationic Pcs and aza-analogs.

\begin{tabular}{lllllll}
\hline Compound & Type & Cells & Irradiation & $\mathrm{IC}_{50}(\mu \mathrm{M})$ & Fluence $\times \mathrm{IC}_{50}$ & $\mathrm{Ref}$ \\
& & & & & \\
\hline A1 & Anionic & HeLa & $\lambda>570 \mathrm{~nm}, 11.2 \mathrm{~J} \mathrm{~cm}^{-2}$ & 5.7 & 63.84 & 6 \\
A2 & Anionic & $\mathrm{J} 774$ & $\lambda>600 \mathrm{~nm}, 48 \mathrm{~J} \mathrm{~cm}^{-2}$ & $\sim 1$ & $\sim 48$ & 7
\end{tabular}




\begin{tabular}{|c|c|c|c|c|c|c|}
\hline & & HepG2 & $\lambda>600 \mathrm{~nm}, 48 \mathrm{~J} \mathrm{~cm}^{-2}$ & $>4$ & $>192$ & 7 \\
\hline & & HEp2 & $\lambda>610 \mathrm{~nm}, 1 \mathrm{~J} \mathrm{~cm}^{-2}$ & 4.5 & 4.5 & 8 \\
\hline & & $\mathrm{HeLa}$ & $\lambda>570 \mathrm{~nm}, 11.2 \mathrm{~J} \mathrm{~cm}^{-2}$ & 5.2 & 58.24 & This work \\
\hline A3 & Anionic & $\mathrm{HeLa}$ & $\lambda>500 \mathrm{~nm}, 31 \mathrm{~J} \mathrm{~cm}^{-2}$ & $>10$ & $>310$ & 9 \\
\hline A4 & Anionic & MGC803 & $\lambda>610 \mathrm{~nm}, 60 \mathrm{~J} \mathrm{~cm}^{-2}$ & 3.05 & 183 & 10 \\
\hline & & Bel-7402 & $\lambda=600-700 \mathrm{~nm}, 53.7 \mathrm{~J} \mathrm{~cm}^{-2}$ & $\sim 18$ & $\sim 966.6$ & 11 \\
\hline A5 & Anionic & MGC803 & $\lambda>610 \mathrm{~nm}, 60 \mathrm{~J} \mathrm{~cm}^{-2}$ & 3.29 & 197.4 & 10 \\
\hline A6 & Anionic & MGC803 & $\lambda>610 \mathrm{~nm}, 60 \mathrm{~J} \mathrm{~cm}^{-2}$ & 3.78 & 226.8 & 10 \\
\hline A7 & Anionic & MGC803 & $\lambda>610 \mathrm{~nm}, 60 \mathrm{~J} \mathrm{~cm}^{-2}$ & 5.30 & 318 & 10 \\
\hline A8 & Anionic & $\mathrm{HeLa}$ & $\lambda>570 \mathrm{~nm}, 11.2 \mathrm{~J} \mathrm{~cm}^{-2}$ & 2.07 & 23.184 & 12 \\
\hline & & $\mathrm{T} 24$ & $\lambda=615-635 \mathrm{~nm}, \sim 4.2 \mathrm{~J} \mathrm{~cm}^{-2}$ & 12.6 & $\sim 52.92$ & 13 \\
\hline & & SK-HEP-1 & $\lambda=615-635 \mathrm{~nm}, \sim 5 \mathrm{~J} \mathrm{~cm}^{-2}$ & 12.6 & $\sim 63$ & 13 \\
\hline A9 & Anionic & $\mathrm{HeLa}$ & $\lambda>570 \mathrm{~nm}, 11.2 \mathrm{~J} \mathrm{~cm}^{-2}$ & 99.8 & 1117.76 & 14 \\
\hline A10 & Anionic & $\mathrm{HeLa}$ & $\lambda>570 \mathrm{~nm}, 11.2 \mathrm{~J} \mathrm{~cm}^{-2}$ & 10.3 & 115.36 & This work \\
\hline A11 & Anionic & HepG2 & $\lambda>610 \mathrm{~nm}, 27 \mathrm{~J} \mathrm{~cm}^{-2}$ & 1.27 & 34.29 & 15 \\
\hline A12 & Anionic & HepG2 & $\lambda>610 \mathrm{~nm}, 48 \mathrm{~J} \mathrm{~cm}^{-2}$ & 1.7 & 81.6 & 16 \\
\hline & & HT29 & $\lambda>610 \mathrm{~nm}, 48 \mathrm{~J} \mathrm{~cm}^{-2}$ & 3.1 & 148.8 & 16 \\
\hline A13 & Anionic & HepG2 & $\lambda>610 \mathrm{~nm}, 48 \mathrm{~J} \mathrm{~cm}^{-2}$ & 3.3 & 158.4 & 16 \\
\hline & & HT29 & $\lambda>610 \mathrm{~nm}, 48 \mathrm{~J} \mathrm{~cm}^{-2}$ & 7.1 & 340.8 & 16 \\
\hline A14 & Anionic & HepG2 & $\lambda>610 \mathrm{~nm}, 27 \mathrm{~J} \mathrm{~cm}^{-2}$ & 3.78 & 102.06 & 17 \\
\hline & & J774 A.1 & $\lambda>610 \mathrm{~nm}, 27 \mathrm{~J} \mathrm{~cm}^{-2}$ & 0.28 & 7.56 & 17 \\
\hline A15 & Anionic & UM-UC3 & $\lambda=620-750 \mathrm{~nm}, 5.4 \mathrm{~J} \mathrm{~cm}^{-2}$ & 2.27 & 5.2 & 18 \\
\hline A16 & Anionic & SK-HEP-1 & $\lambda=615-635 \mathrm{~nm}, \sim 0.4 \mathrm{~J} \mathrm{~cm}^{-2}$ & 13 & $\sim 63.84$ & 13 \\
\hline
\end{tabular}

$\begin{array}{lllllll}\text { C1 } & \text { Cationic } & \text { HeLa } & \lambda>570 \mathrm{~nm}, 11.2 \mathrm{~J} \mathrm{~cm}^{-2} & 0.037 & 0.4144 & 19 \\ \text { C2 } & \text { Cationic } & \text { SK-MEL-28 } & \lambda>570 \mathrm{~nm}, 11.2 \mathrm{~J} \mathrm{~cm}^{-2} & 0.54 & 6.048 & 20 \\ & & \text { HeLa } & \lambda>570 \mathrm{~nm}, 11.2 \mathrm{~J} \mathrm{~cm}^{-2} & 0.32 & 3.584 & 20 \\ \text { C3 } & \text { Cationic } & \text { SK-MEL-28 } & \lambda>570 \mathrm{~nm}, 11.2 \mathrm{~J} \mathrm{~cm}^{-2} & 0.31 & 3.472 & 20 \\ & & \text { HeLa } & \lambda>570 \mathrm{~nm}, 11.2 \mathrm{~J} \mathrm{~cm}^{-2} & 0.22 & 2.464 & 20 \\ \text { C4 } & \text { Cationic } & \text { Hep2 } & \lambda>640 \mathrm{~nm}, 52.2 \mathrm{~J} \mathrm{~cm}^{-2} & 3.70 & 193.14 & 20 \\ & & \text { HeLa } & \lambda>570 \mathrm{~nm}, 11.2 \mathrm{~J} \mathrm{~cm}^{-2} & 0.10 & 1.12 & 21 \\ \text { C5 } & \text { Cationic } & \text { HeLa } & \lambda>570 \mathrm{~nm}, 11.2 \mathrm{~J} \mathrm{~cm}^{-2} & 0.26 & 2.912 & 22 \\ \text { C6 } & \text { Cationic } & \text { HeLa } & \lambda>570 \mathrm{~nm}, 11.2 \mathrm{~J} \mathrm{~cm}^{-2} & 0.15 & 1.68 & 12 \\ \text { C7 } & \text { Cationic } & \text { HeLa } & \lambda>570 \mathrm{~nm}, 11.2 \mathrm{~J} \mathrm{~cm}^{-2} & 0.87 & 9.744 & 12 \\ \text { C8 } & \text { Cationic } & \text { SK-MEL-28 } & \lambda>570 \mathrm{~nm}, 11.2 \mathrm{~J} \mathrm{~cm}^{-2} & 0.0038 & 0.04256 & 12 \\ & & \text { A549 } & \lambda>570 \mathrm{~nm}, 11.2 \mathrm{~J} \mathrm{~cm}^{-2} & 0.0038 & 0.04256 & 12 \\ & & \text { MCF7 } & \lambda>570 \mathrm{~nm}, 11.2 \mathrm{~J} \mathrm{~cm}^{-2} & 0.0052 & 0.05824 & 12 \\ & & \text { HeLa } & \lambda>570 \mathrm{~nm}, 11.2 \mathrm{~J} \mathrm{~cm}^{-2} & 0.0028 & 0.03136 & 12\end{array}$




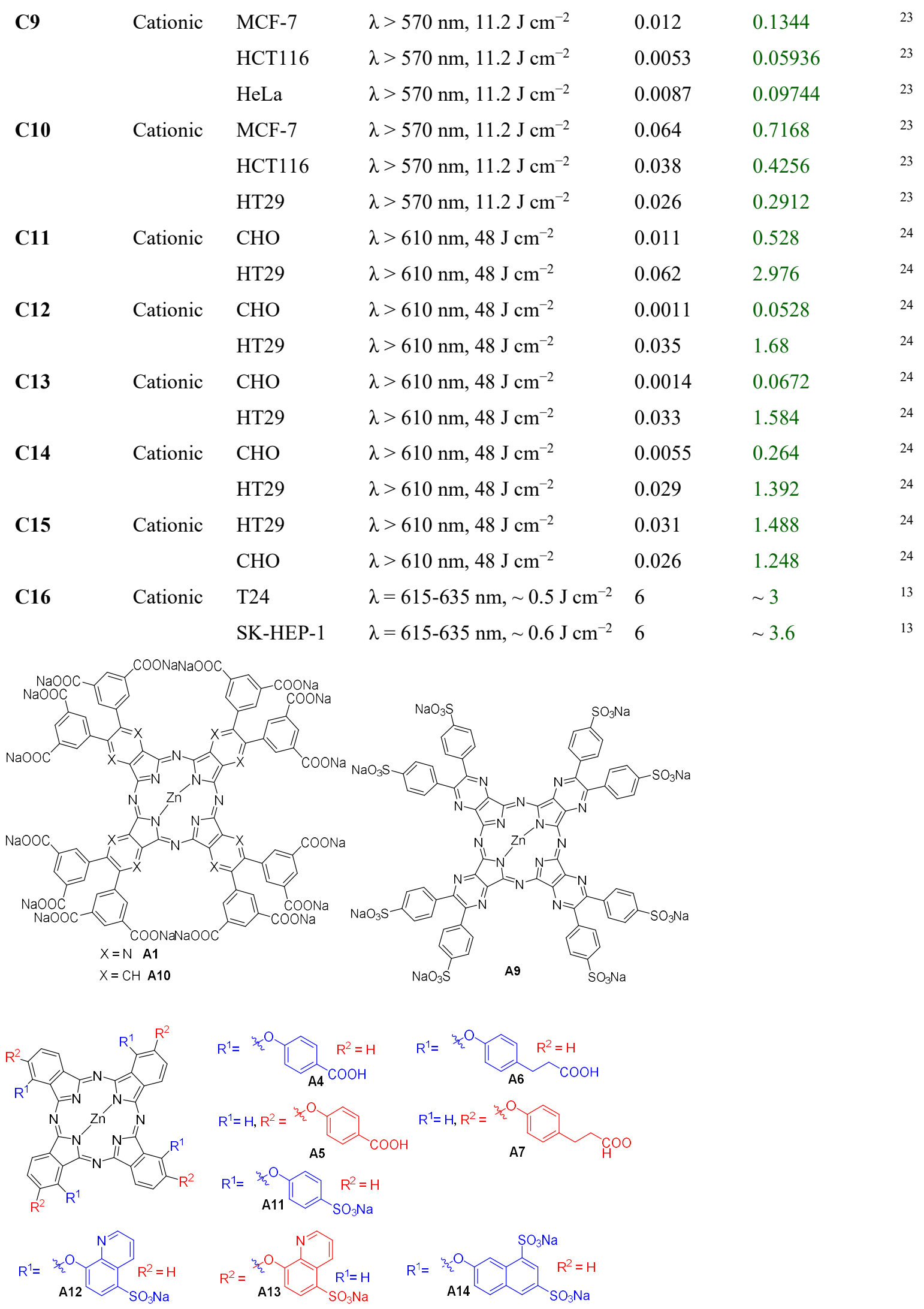



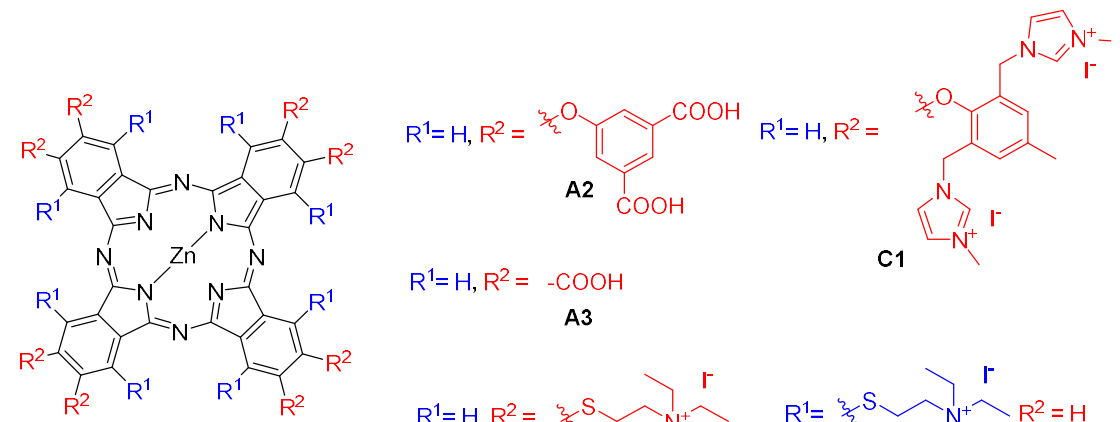

A3

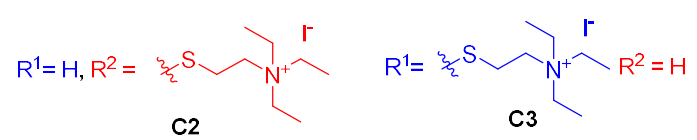

$\mathrm{R}^{1}=\mathrm{H}, \mathrm{R}^{2}=-\mathrm{PO} 3 \mathrm{H} 2$

A15
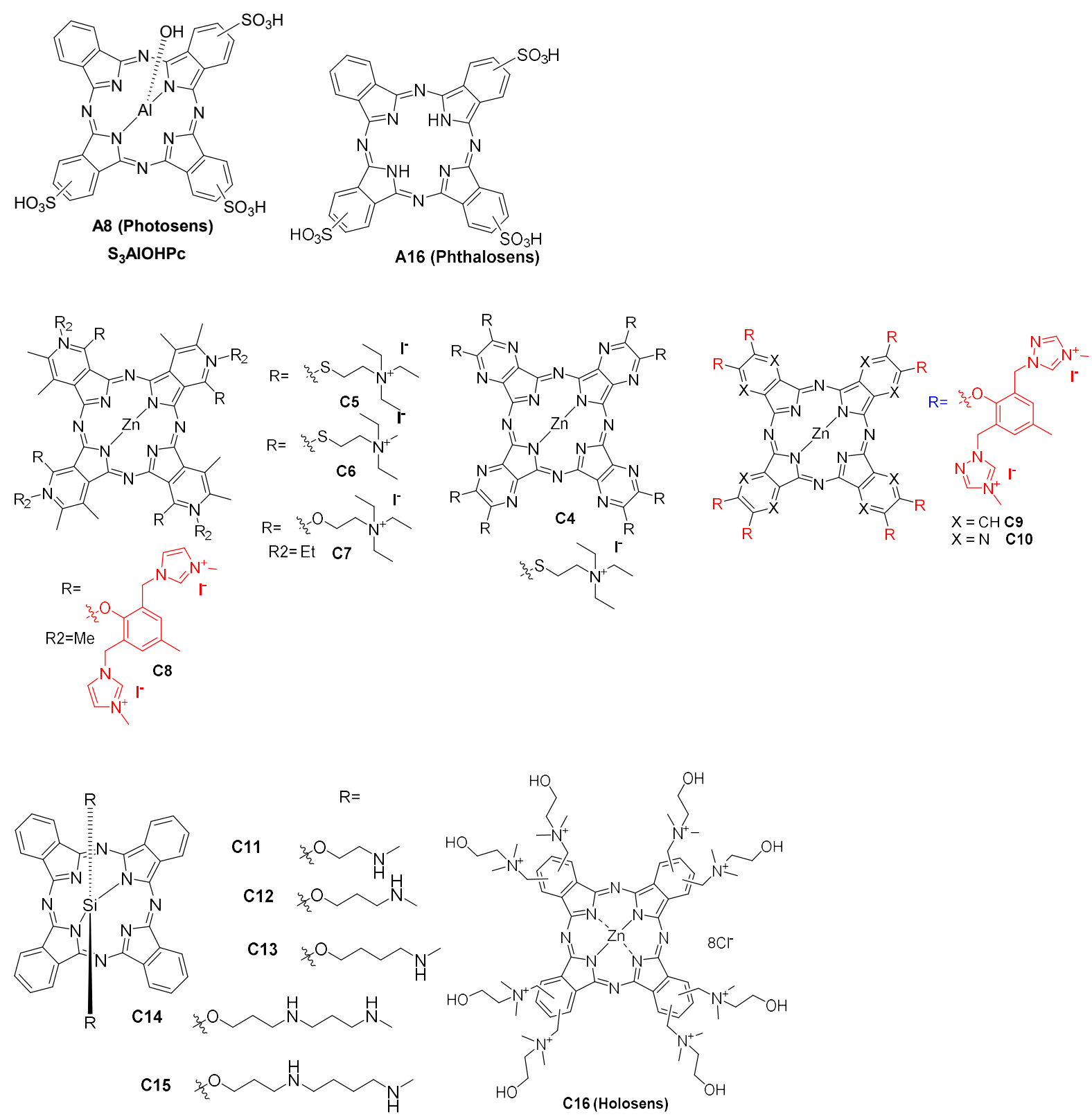
a)
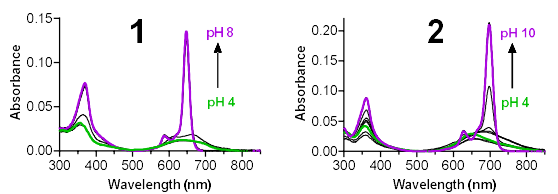

b)
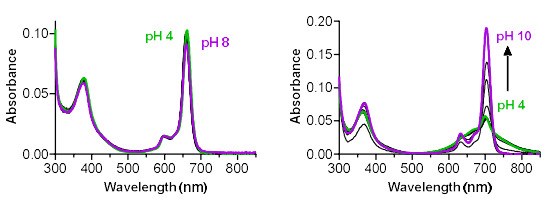

c)
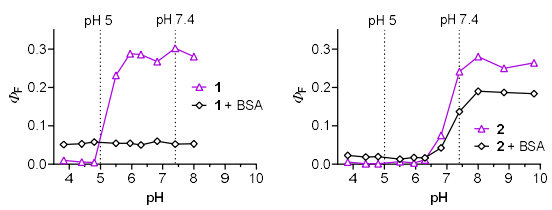
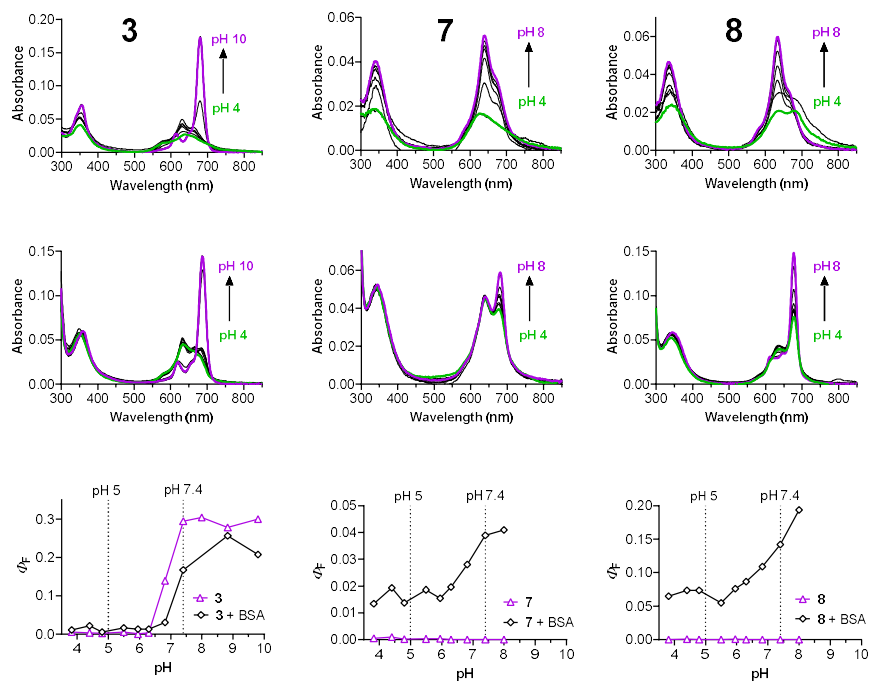

Figure S3. Anionic derivatives. a) Changes in absorption spectra of compounds 1-3, 7, 8 (c = $1 \mu \mathrm{M})$ in Britton-Robinson buffer of different $\mathrm{pH}(\mathrm{I}=0.15 \mathrm{M})$. b) Changes in absorption spectra of compounds 1-3, 7, $8(\mathrm{c}=1 \mu \mathrm{M})$ in Britton-Robinson buffer of different $\mathrm{pH}(\mathrm{I}=$ $0.15 \mathrm{M})$ in the presence of BSA $(20 \mu \mathrm{M})$. c) Changes in $\Phi_{\mathrm{F}}$ values of compounds 1-3, 7, 8 (c $=1 \mu \mathrm{M})$ in Britton-Robinson buffer of different $\mathrm{pH}(\mathrm{I}=0.15 \mathrm{M})$ in absence (magenta) or presence of BSA (black, $20 \mu \mathrm{M}$ ).

a)

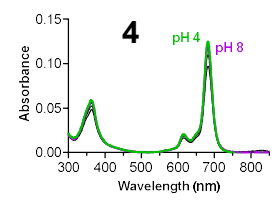

b)

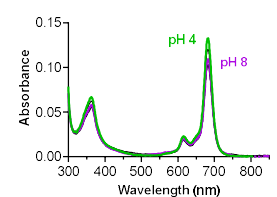

c)

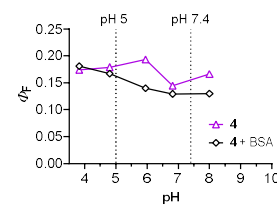

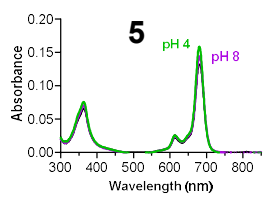
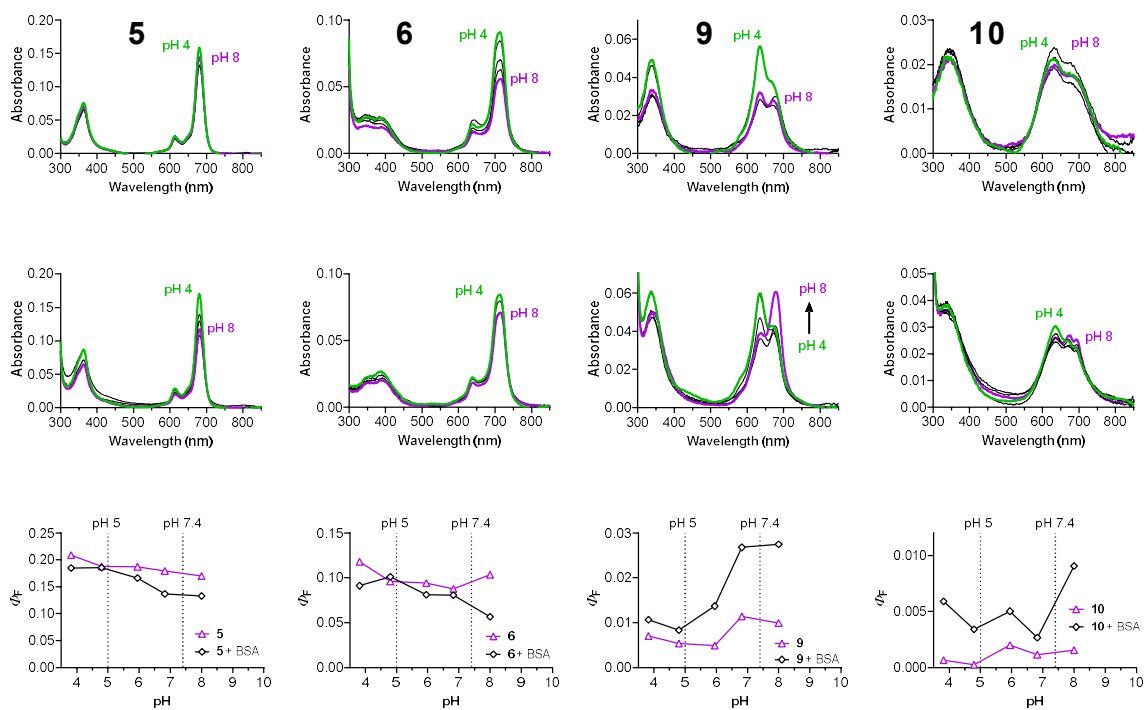

Figure S4. Cationic derivatives. a) Changes in absorption spectra of compounds 4-6, 9, 10 (c $=1 \mu \mathrm{M})$ in Britton-Robinson buffer of different $\mathrm{pH}(\mathrm{I}=0.15 \mathrm{M})$. b) Changes in absorption spectra of compounds 4-6, 9, $10(\mathrm{c}=1 \mu \mathrm{M})$ in Britton-Robinson buffer of different $\mathrm{pH}(\mathrm{I}=$ $0.15 \mathrm{M})$ in the presence of BSA $(20 \mu \mathrm{M})$. c) Changes in $\Phi_{\mathrm{F}}$ values of compounds 4-6, 9, 10 (c $=1 \mu \mathrm{M})$ in Britton-Robinson buffer of different $\mathrm{pH}(\mathrm{I}=0.15 \mathrm{M})$ in absence (magenta) or presence of BSA (black, $20 \mu \mathrm{M}$ ). 
a)

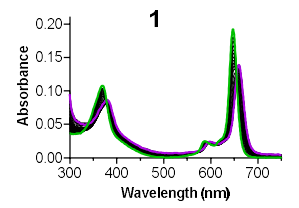

b)

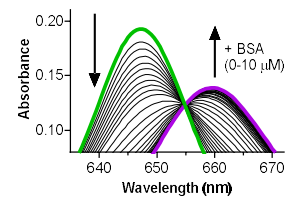

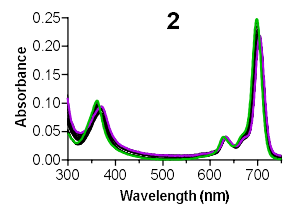
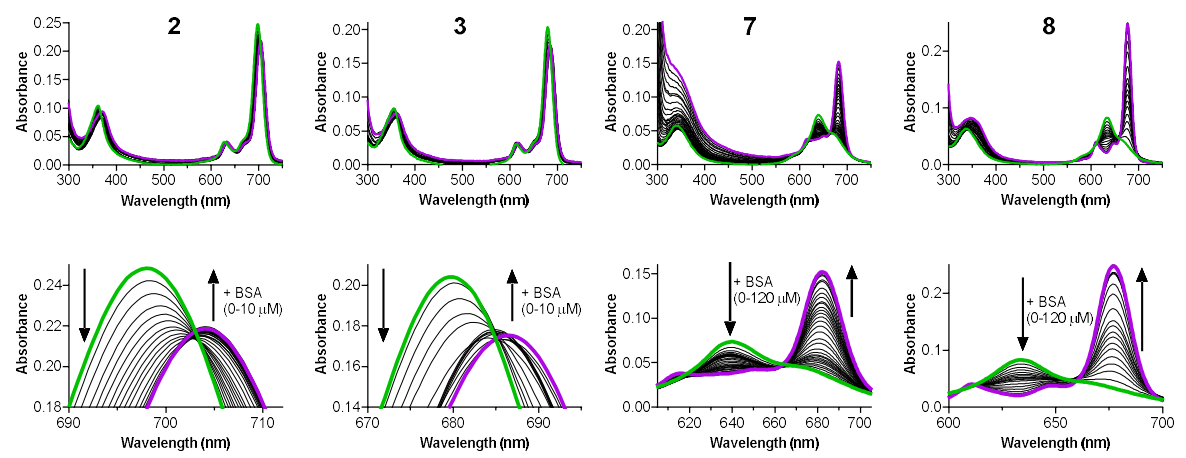

Figure S5. Anionic derivatives. a) Changes in absorption spectra of $\mathbf{1 - 3}, \mathbf{7 ,} 8$ in $\mathrm{PBS}$ (c $=1$ $\mu \mathrm{M}$ ) upon addition of increasing amount of BSA ranging from $0 \mu \mathrm{M}$ (green) to $10 / 120 \mu \mathrm{M}$ (magenta). b) Detail of the Q-band.

a)

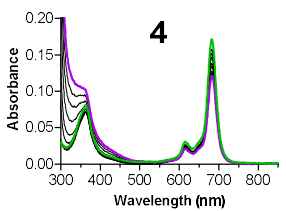

b)

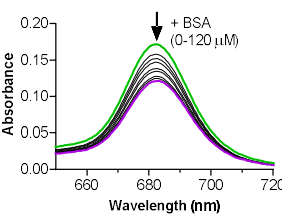

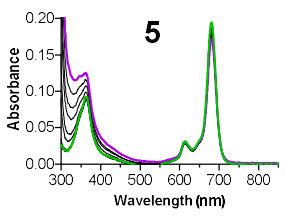
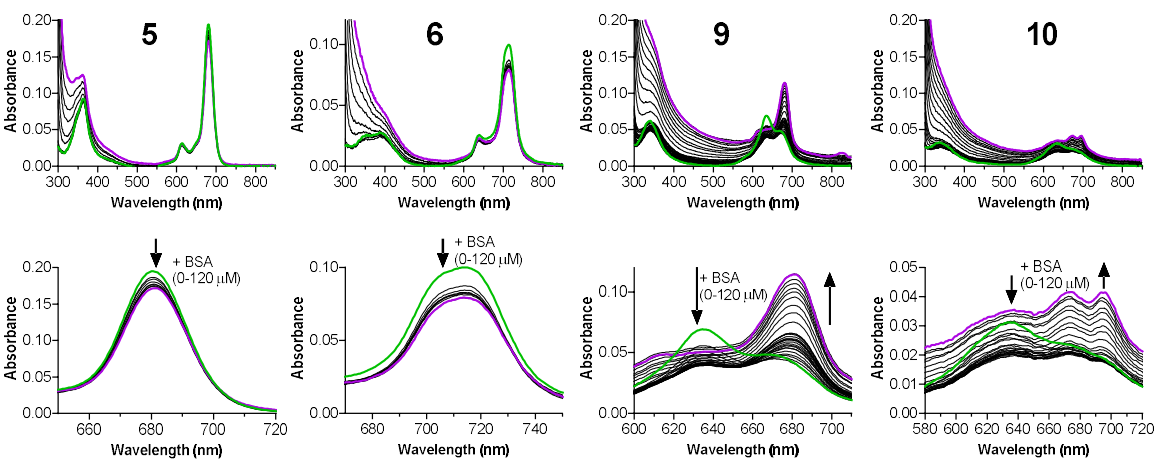

Figure S6. Cationic derivatives. a) Changes in absorption spectra of 4-6, 9, 10 in PBS (c = 1 $\mu \mathrm{M}$ ) upon addition of increasing amount of BSA ranging from $0 \mu \mathrm{M}$ (green) to $120 \mu \mathrm{M}$ (magenta). b) Detail of the Q-band.

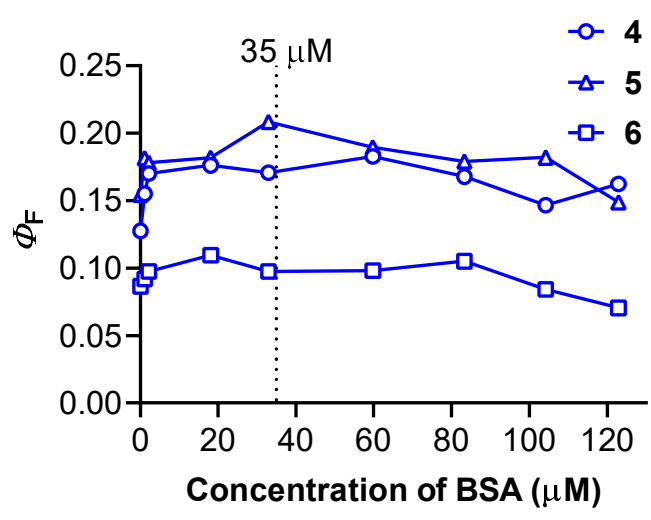

Figure S7. Fluorescence quantum yield of 4-6 in dependence on added BSA. The typical concentration of BSA in SCM $(35 \mu \mathrm{M})$ is indicated by vertical dotted line. 

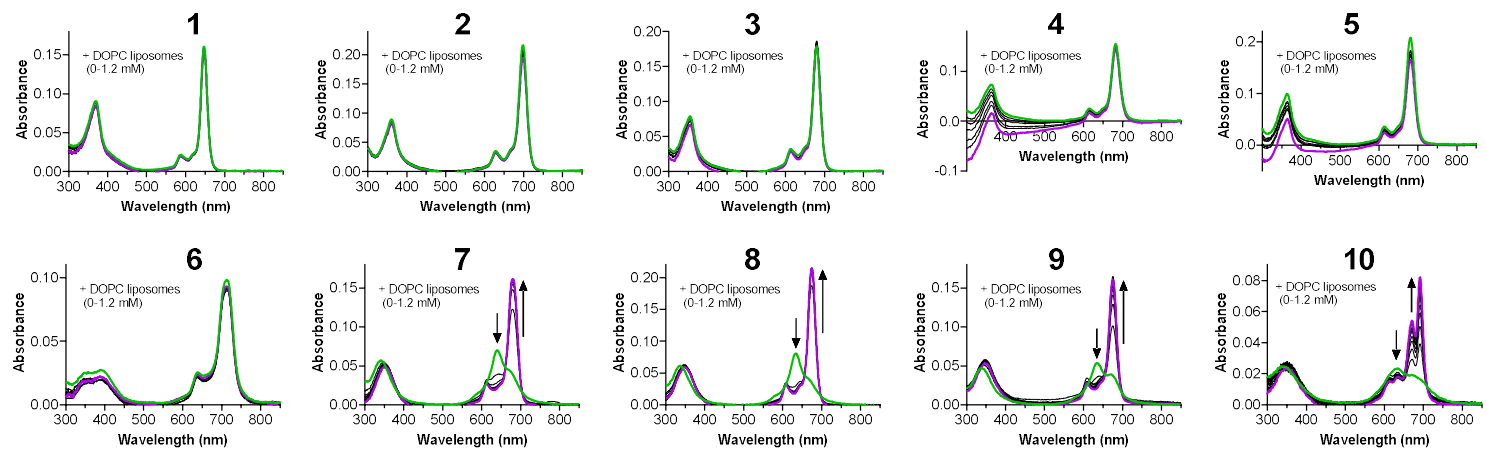

Figure S8. Changes in absorption spectra of Pcs 1-10 in PBS $(1 \mu \mathrm{M})$ upon addition of DOPC liposomes from $0 \mathrm{mM}$ (green) to $1.2 \mathrm{mM}$ (magenta). Changes in background of $\mathbf{4}$ and $\mathbf{5}$ are due to different scattering of the light on the liposomal suspension.
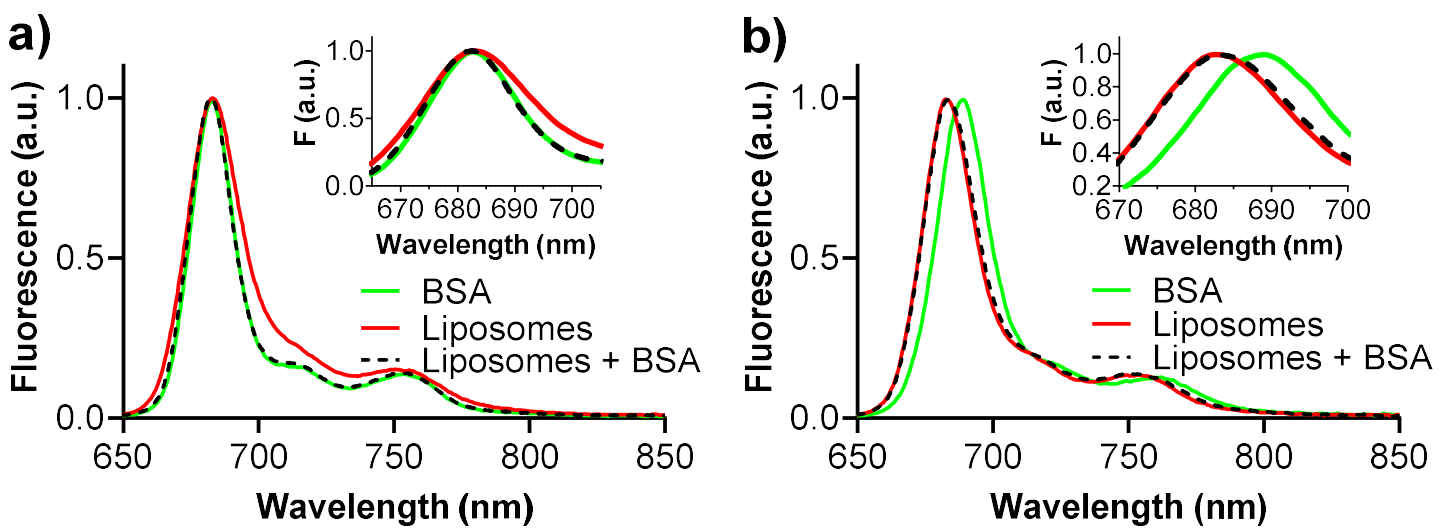

Figure S9. Normalized emission spectra $\left(\lambda_{\mathrm{exc}}=608 \mathrm{~nm}, \mathrm{c}=1 \mu \mathrm{M}\right.$ in PBS) of 8 (a) and 9 (b) in BSA (35 $\mu \mathrm{M}$, green), in DOPC liposomes (1.2 mM, red), and in presence of DOPC liposomes after addition of BSA (black dashed). Inset - detail in the emission maxima. 


\section{In vitro experiments}

\section{Cellular uptake in presence of dynasore}
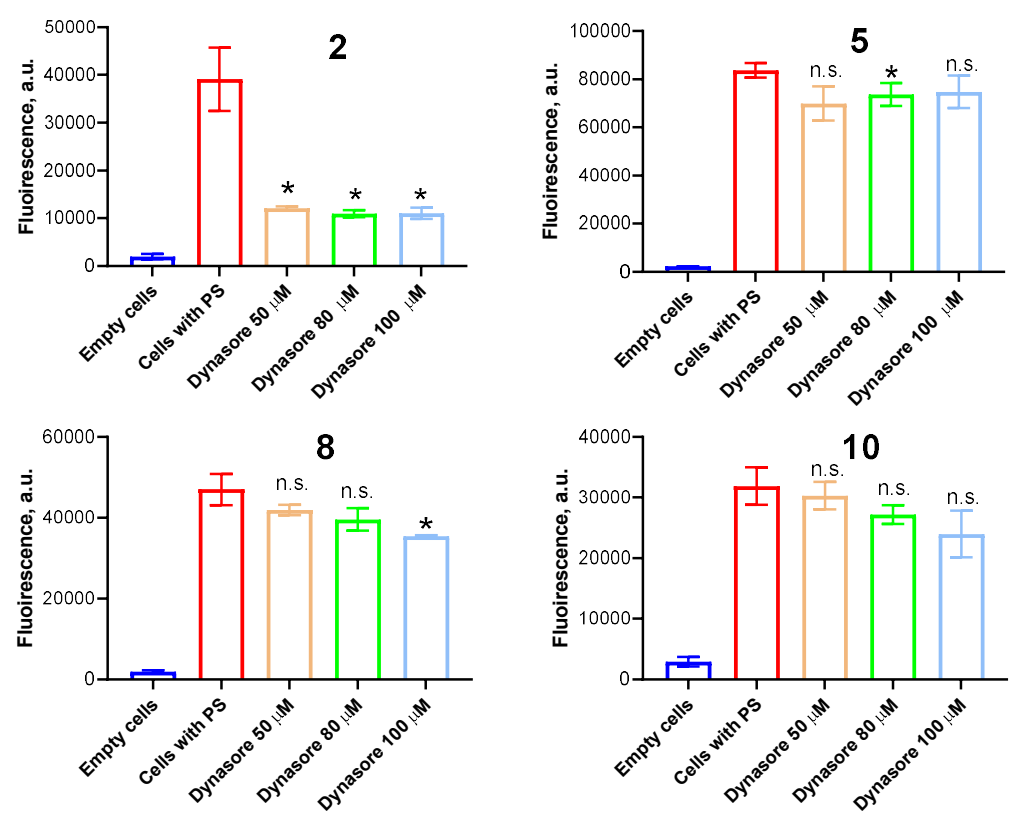

Fig. S10. Comparison of cellular uptake of compounds 2, 5, 8 and 10 on HeLa cells in the absence (red column) and presence of different concentrations of dynasore, an inhibitor of endocytosis. Control experiment without any inhibitor and without any PS is shown in blue. Statistical significance is calculated against cells with PS only. n.s. (nonsignificant), $p>0.05$; $*, p<0.05$ (Welch's t-test). Experiments were performed in triplicate.

\section{Assessment of photodynamic activity and dark toxicity}

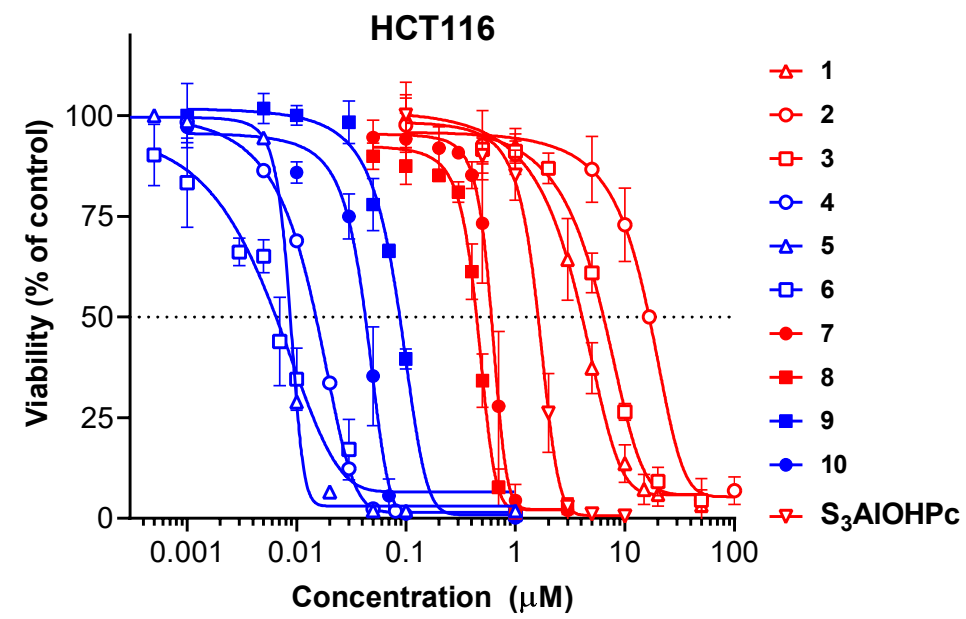

Figure S11. Photodynamic activity of compounds 1-10 and S3AIOHPc on HCT-116 cells in $\operatorname{SCM}\left(\lambda>570 \mathrm{~nm}, 12.4 \mathrm{~mW} \mathrm{~cm}{ }^{-2}, 15 \mathrm{~min}, 11.2 \mathrm{~J} \mathrm{~cm}^{-2}\right)$. Anionic compounds are displayed in red and cationic compounds in blue. 


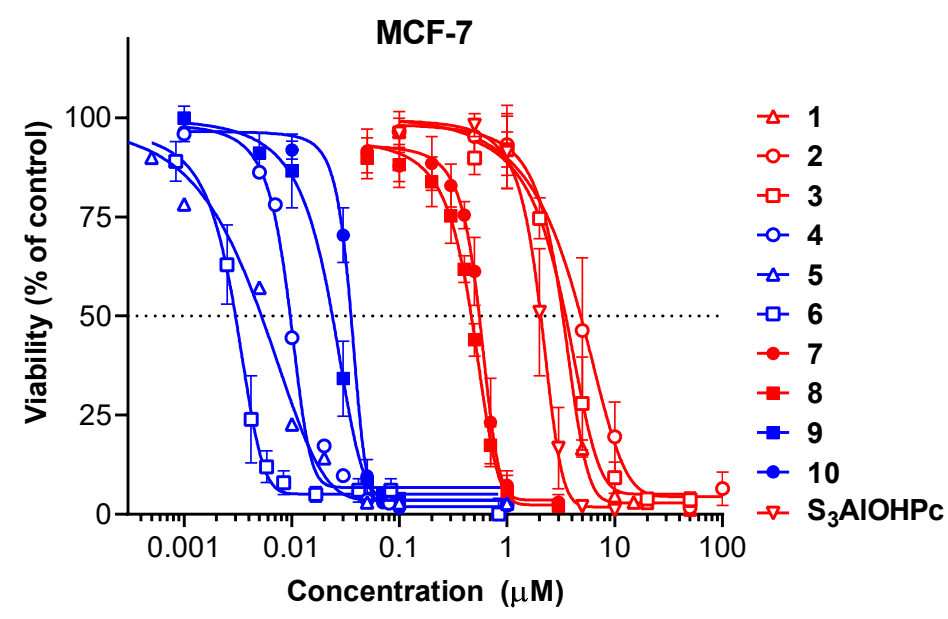

Figure S12. Photodynamic activity of compounds 1-10 and S3AlOHPc on MCF-7 cells in SCM $\left(\lambda>570 \mathrm{~nm}, 12.4 \mathrm{~mW} \mathrm{~cm}^{-2}, 15 \mathrm{~min}, 11.2 \mathrm{~J} \mathrm{~cm}^{-2}\right)$. Anionic compounds are displayed in red and cationic compounds in blue.

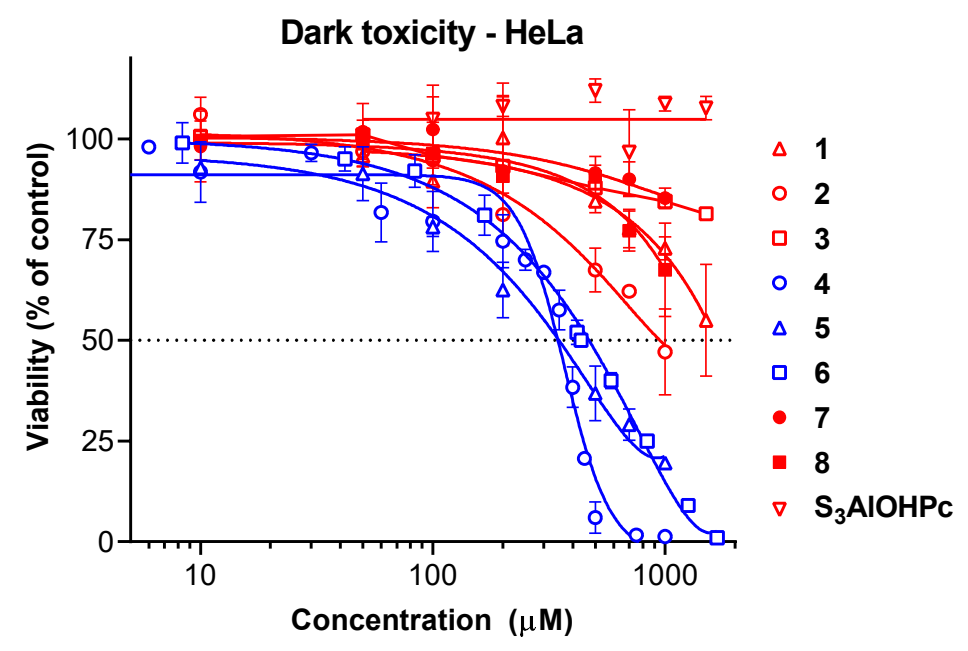

Figure S13. Dark toxicity of compounds 1-8 and $\mathbf{S}_{3} \mathrm{AlOHPc}$ on HeLa cells in SCM. Compounds 9 and $\mathbf{1 0}$ precipitated at concentration over $150 \mu \mathrm{M}$ and $100 \mu \mathrm{M}$, respectively, without detectable toxicity. Anionic compounds are displayed in red and cationic compounds in blue. 


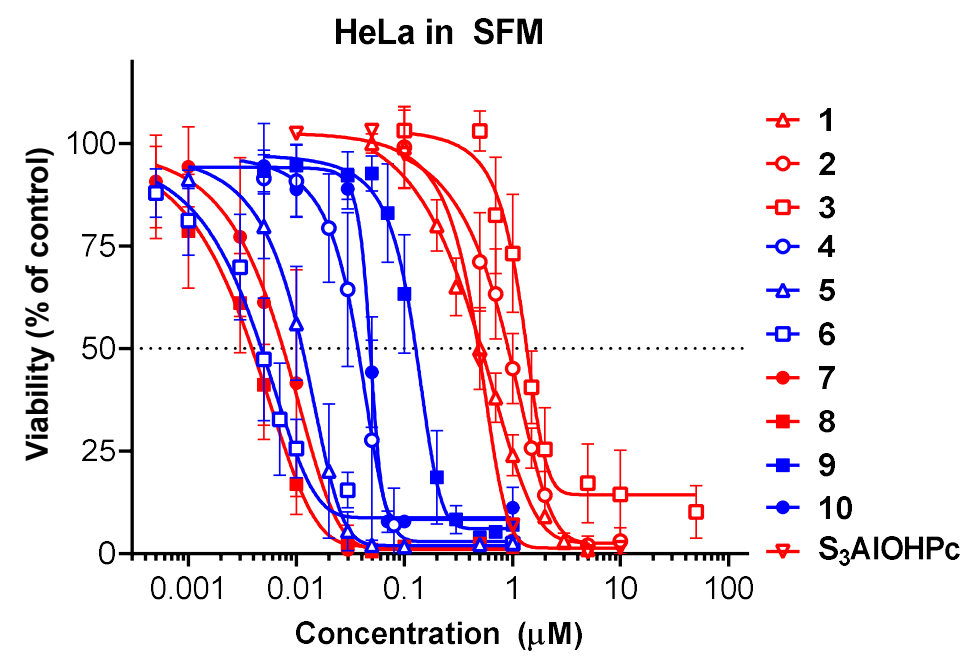

Figure S14. Photodynamic activity of compounds 1-10 and S3AlOHPc on HeLa cells in SFM $\left(\lambda>570 \mathrm{~nm}, 12.4 \mathrm{~mW} \mathrm{~cm}{ }^{-2}, 15 \mathrm{~min}, 11.2 \mathrm{~J} \mathrm{~cm}^{-2}\right)$. Anionic compounds are displayed in red and cationic compounds in blue.

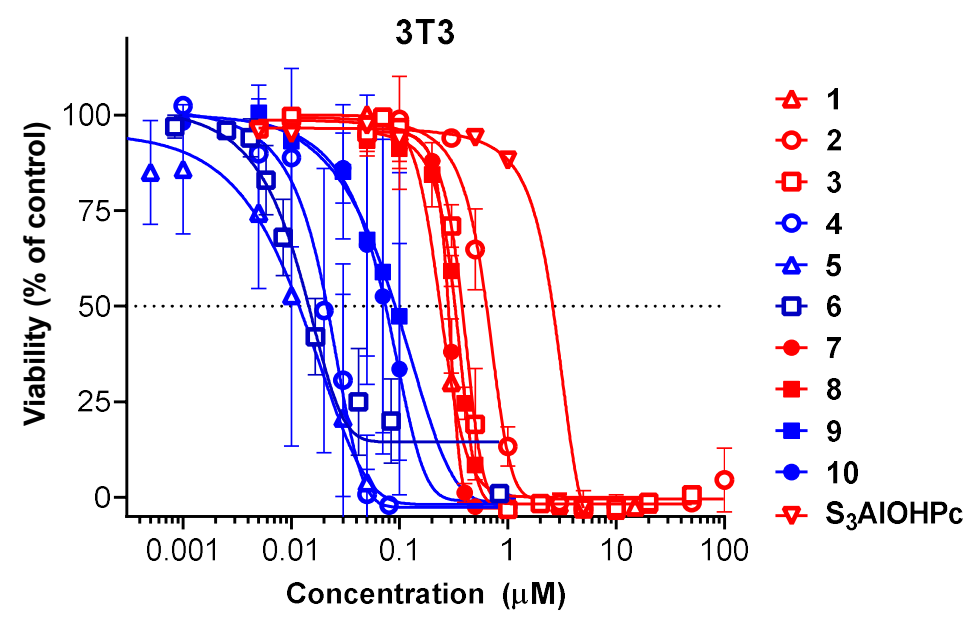

Figure S15. Photodynamic activity of compounds 1-10 and $\mathbf{S}_{3} \mathrm{AlOHPc}$ on $3 \mathrm{~T} 3$ cells in SCM $\left(\lambda>570 \mathrm{~nm}, 12.4 \mathrm{~mW} \mathrm{~cm}{ }^{-2}, 15 \mathrm{~min}, 11.2 \mathrm{~J} \mathrm{~cm}^{-2}\right)$. Anionic compounds are displayed in red and cationic compounds in blue. 
Subcellular localization and relocalization
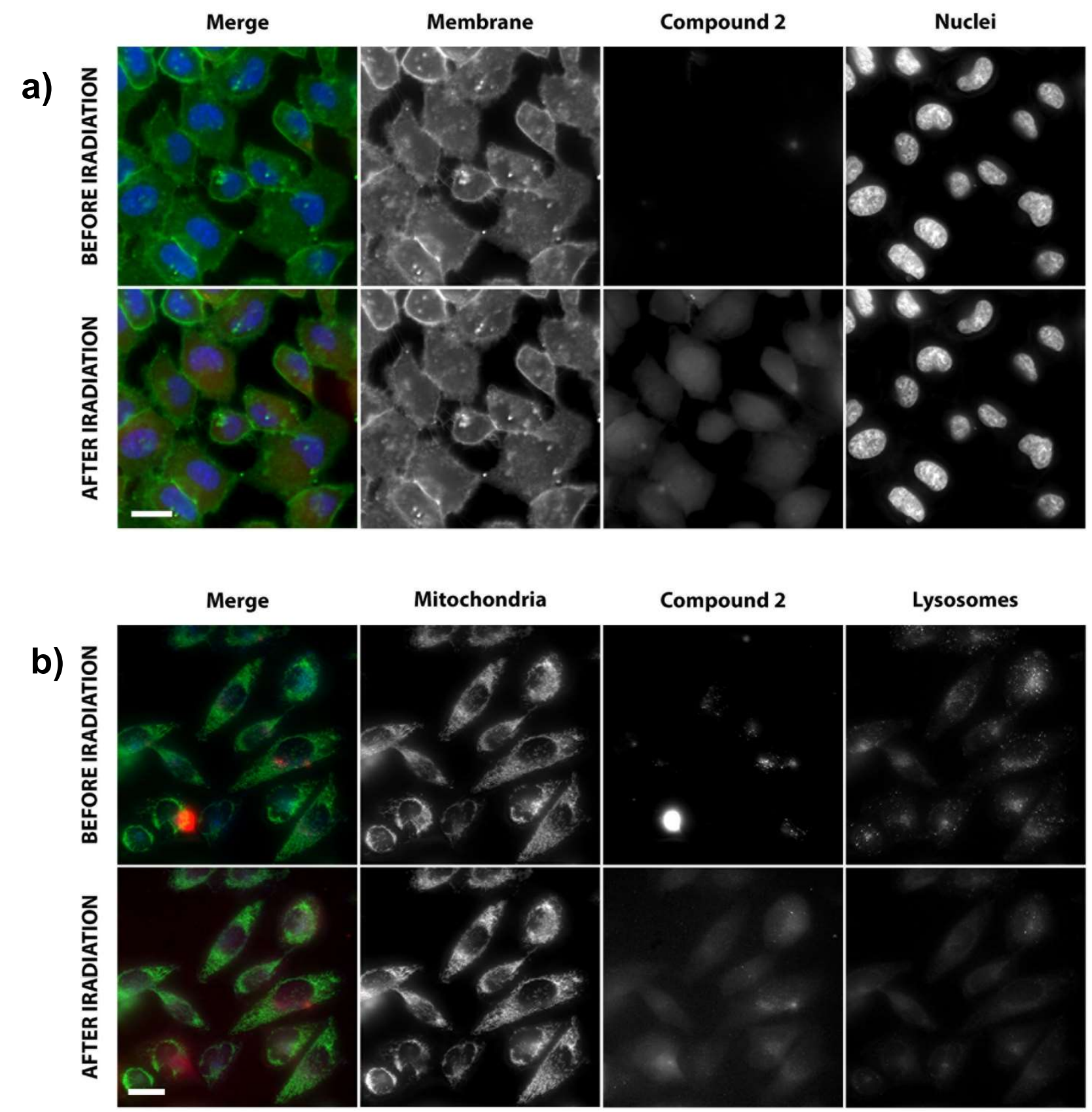

Figure S16. Subcellular localization of 2 (red) before and after irradiation. a) Cells were stained for membrane (green) and nuclei (blue). b) Cells were stained for mitochondria (green) and lysosomes (blue) by organelle-specific fluorescent probes. Bar represents $24 \mu \mathrm{m}$. 

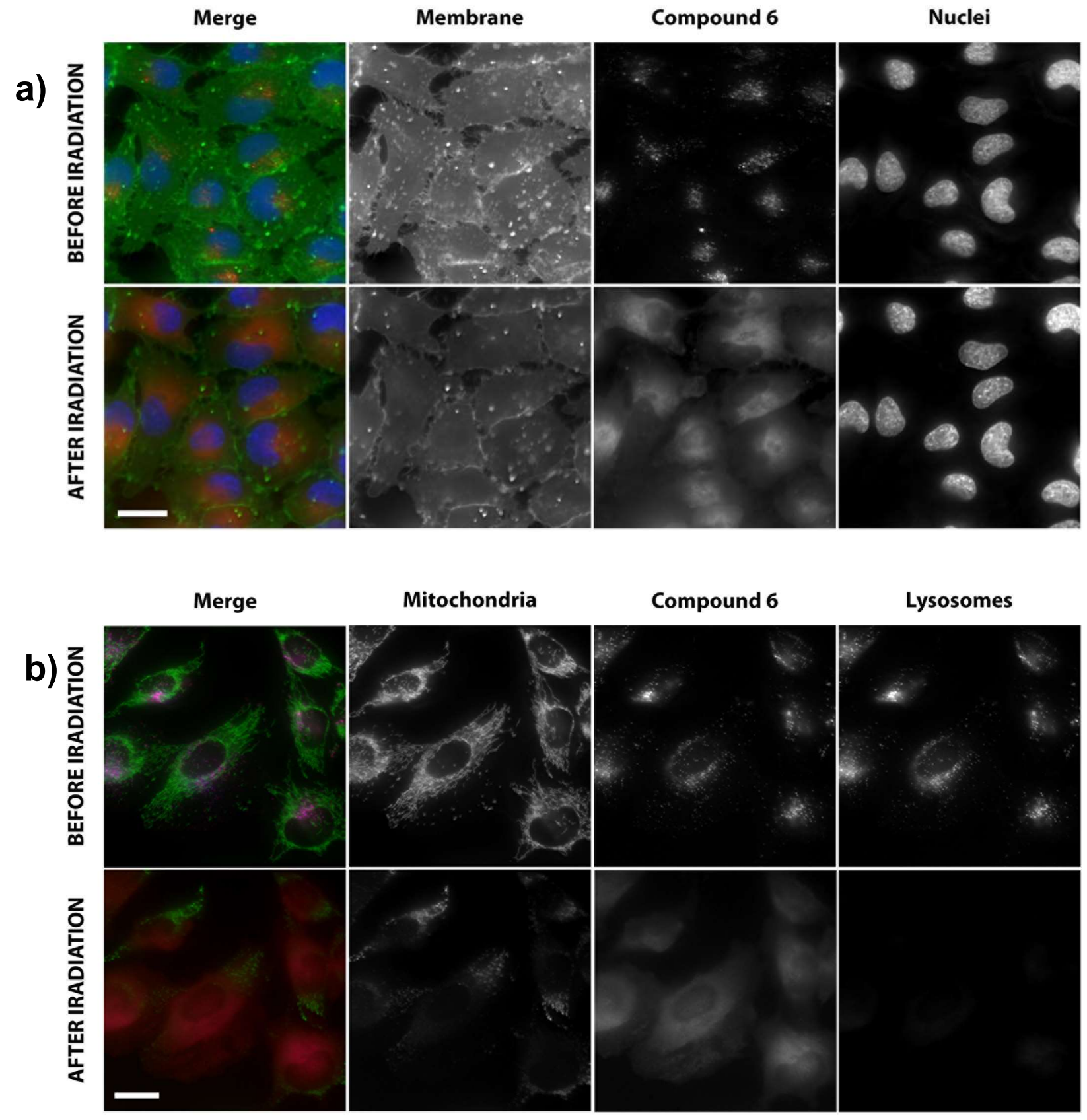

Figure S17. Subcellular localization of 6 (red) before and after irradiation. a) Cells were stained for membrane (green) and nuclei (blue). b) Cells were stained for mitochondria (green) and lysosomes (blue) by organelle-specific fluorescent probes. Bar represents $24 \mu \mathrm{m}$. 

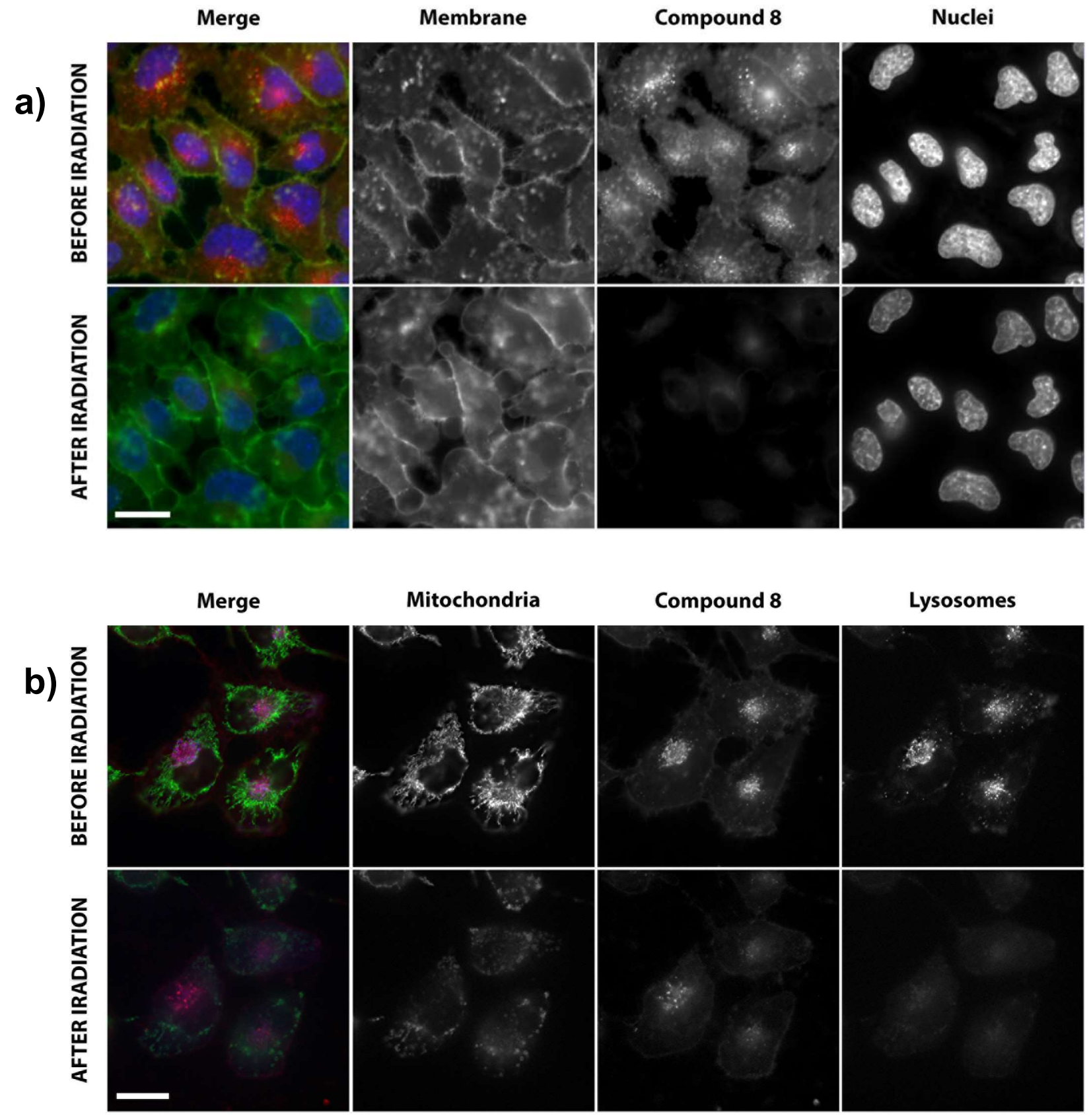

Figure S18. Subcellular localization of $\mathbf{8}$ (red) before and after irradiation. a) Cells were stained for membrane (green) and nuclei (blue). b) Cells were stained for mitochondria (green) and lysosomes (blue) by organelle-specific fluorescent probes. Bar represents $24 \mu \mathrm{m}$. 

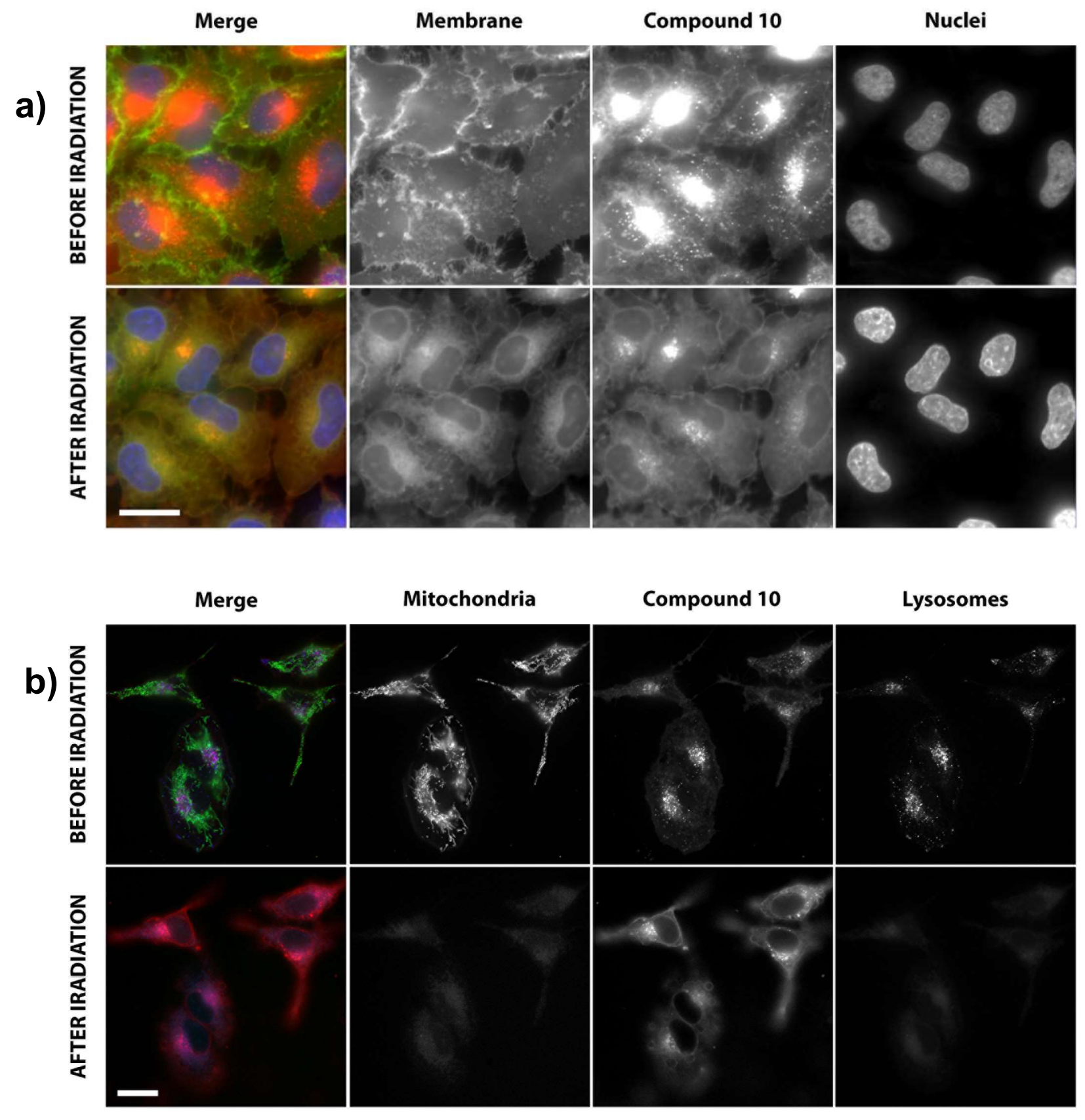

Figure S19. Subcellular localization of $\mathbf{1 0}$ (red) before and after irradiation. a) Cells were stained for membrane (green) and nuclei (blue). b) Cells were stained for mitochondria (green) and lysosomes (blue) by organelle-specific fluorescent probes. Bar represents $24 \mu \mathrm{m}$. 

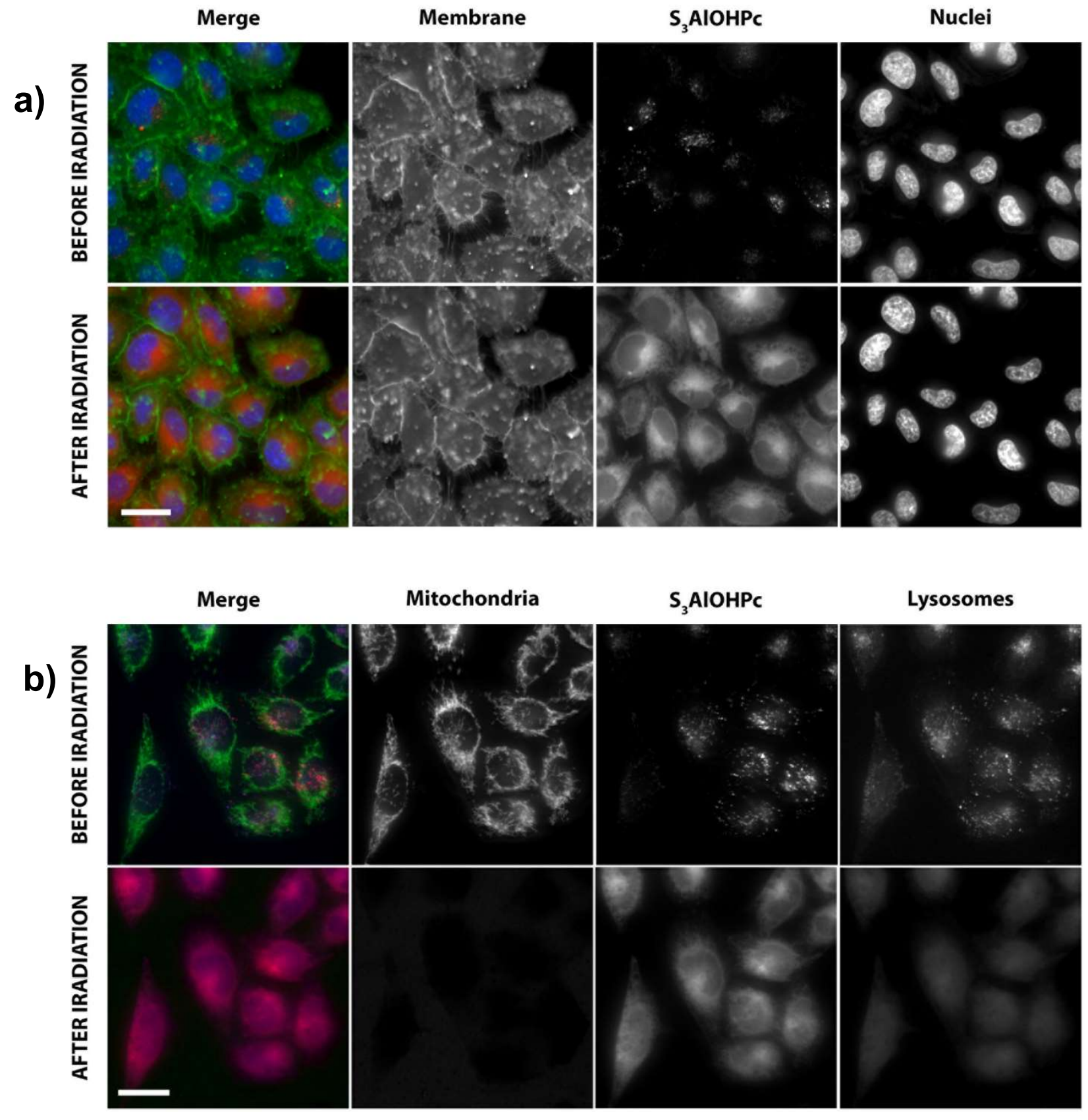

Figure S20. Subcellular localization of $\mathbf{S}_{3} \mathbf{A I O H P c}$ (red) before and after irradiation. a) Cells were stained for membrane (green) and nuclei (blue). b) Cells were stained for mitochondria (green) and lysosomes (blue) by organelle-specific fluorescent probes. Bar represents $24 \mu \mathrm{m}$. 
Morphological changes

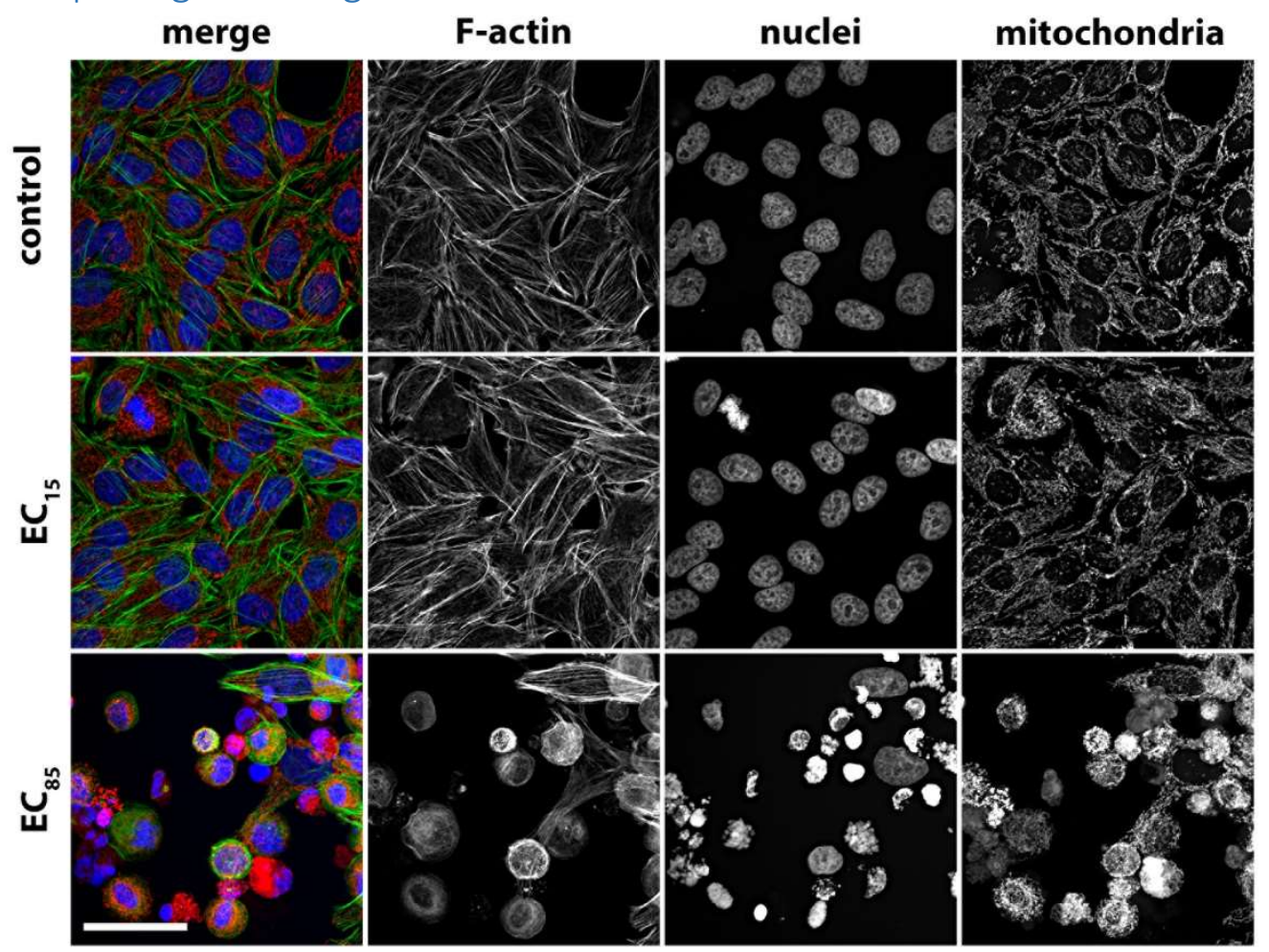

Figure S21. Changes of cellular morphology induced by photodynamic action of compound 2 $24 \mathrm{~h}$ post irradiation $\left(\lambda>570 \mathrm{~nm}, 12.4 \mathrm{~mW} \mathrm{~cm}^{-2}, 15 \mathrm{~min}, 11.2 \mathrm{~J} \mathrm{~cm}^{-2}\right)$. Blue - nuclei, red mitochondria, green $-\mathrm{F}$-actin. Bar represents $50 \mu \mathrm{m}$.

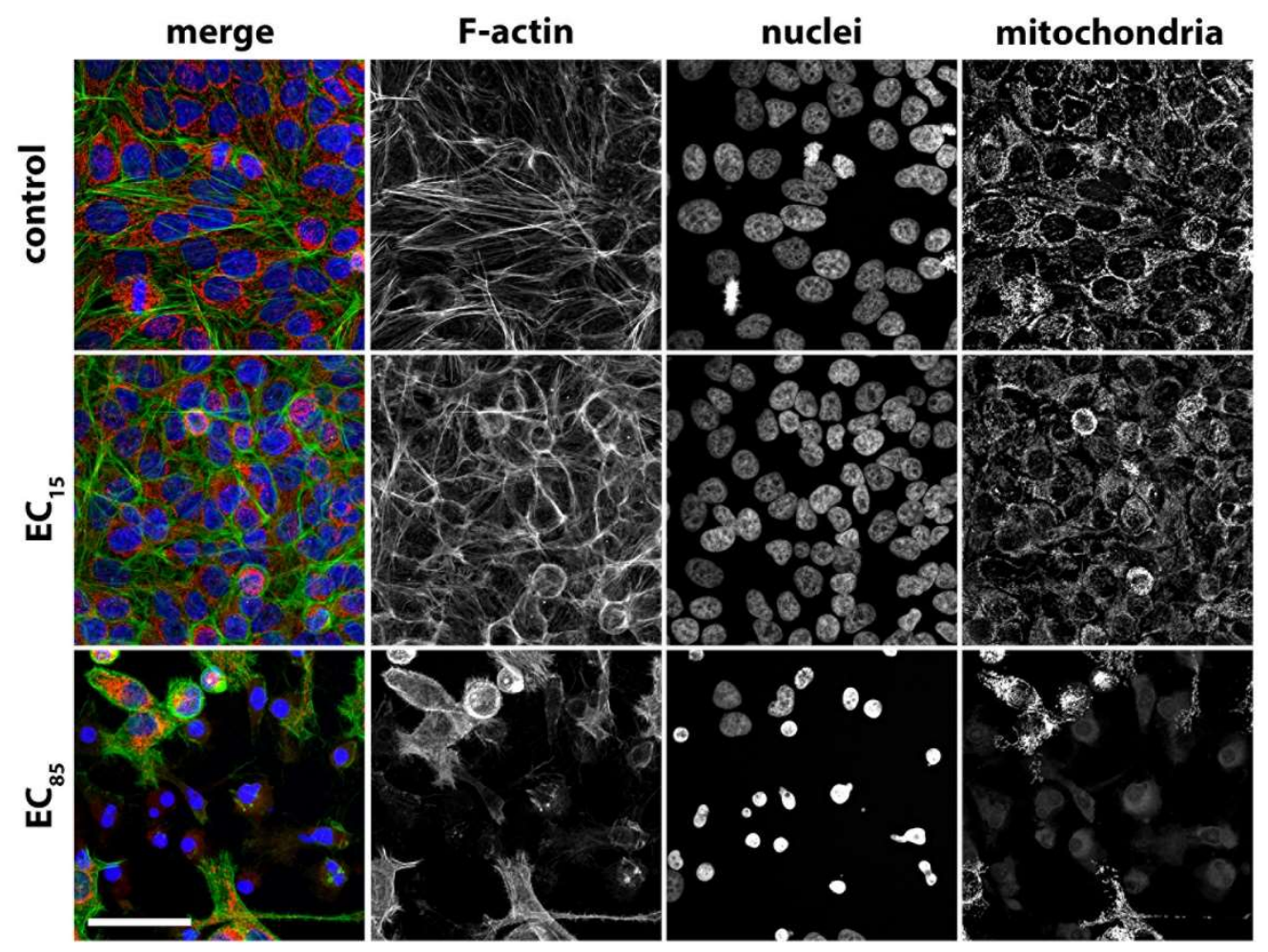

Figure S22. Changes of cellular morphology induced by photodynamic action of compound 5 $24 \mathrm{~h}$ post irradiation $\left(\lambda>570 \mathrm{~nm}, 12.4 \mathrm{~mW} \mathrm{~cm}^{-2}, 15 \mathrm{~min}, 11.2 \mathrm{~J} \mathrm{~cm}^{-2}\right)$. Blue - nuclei, red mitochondria, green $-\mathrm{F}$-actin. Bar represents $50 \mu \mathrm{m}$. 


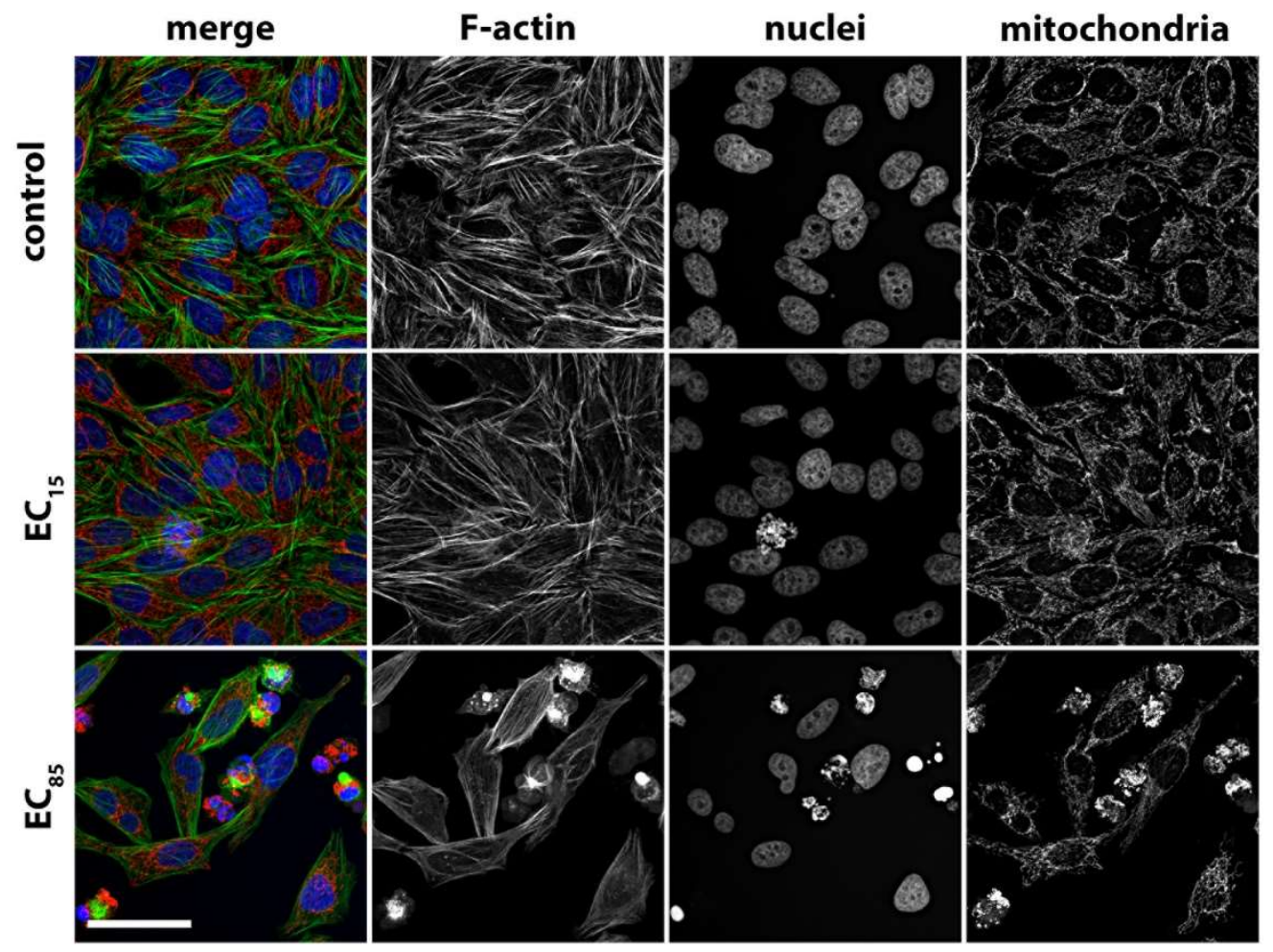

Figure S23. Changes of cellular morphology induced by photodynamic action of compound $\mathbf{8}$ $24 \mathrm{~h}$ post irradiation $\left(\lambda>570 \mathrm{~nm}, 12.4 \mathrm{~mW} \mathrm{~cm}^{-2}, 15 \mathrm{~min}, 11.2 \mathrm{~J} \mathrm{~cm}^{-2}\right)$. Blue - nuclei, red mitochondria, green $-\mathrm{F}$-actin. Bar represents $50 \mu \mathrm{m}$.

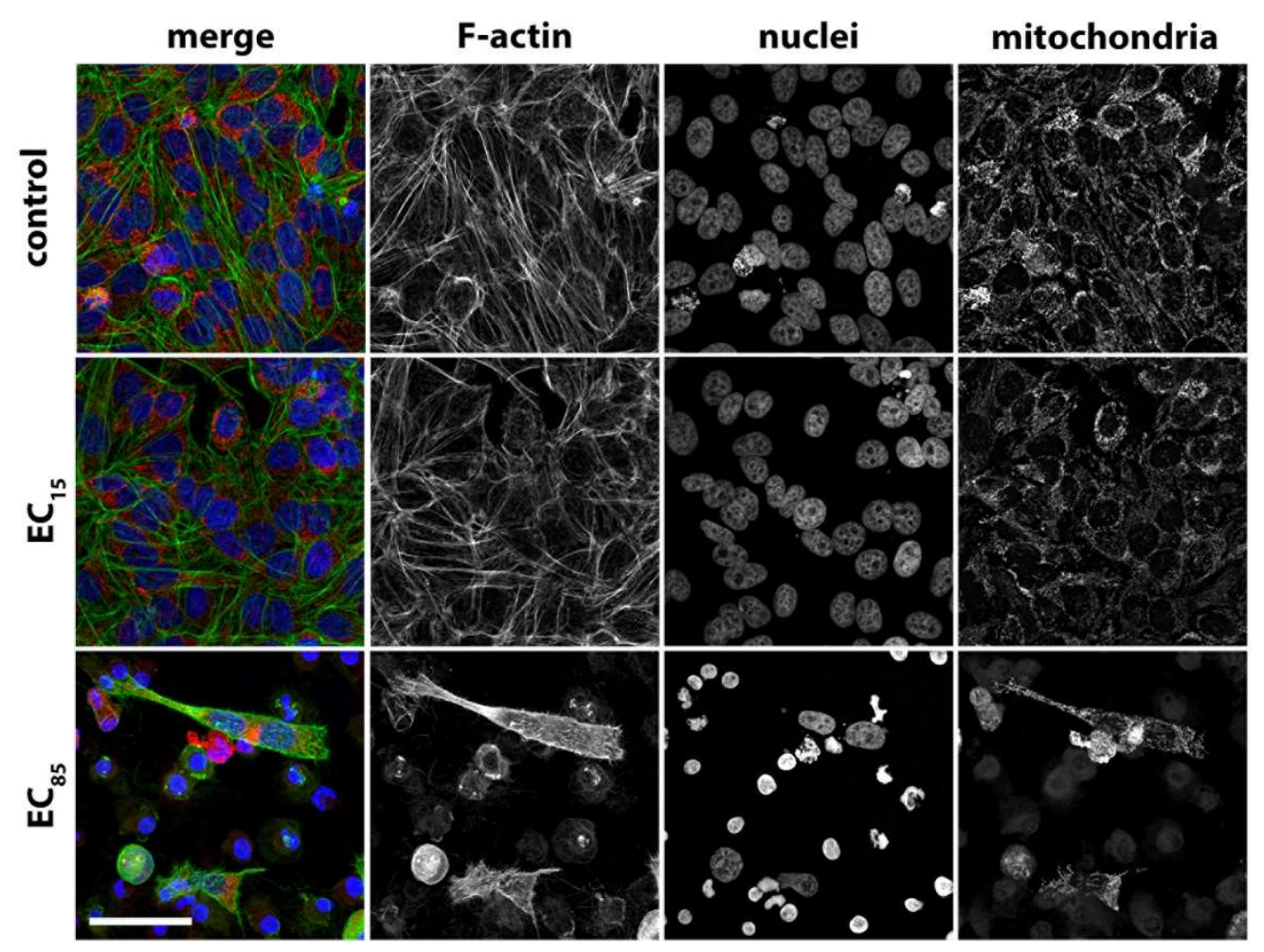

Figure S24. Changes of cellular morphology induced by photodynamic action of compound $\mathbf{1 0}$ $24 \mathrm{~h}$ post irradiation $\left(\lambda>570 \mathrm{~nm}, 12.4 \mathrm{~mW} \mathrm{~cm}^{-2}, 15 \mathrm{~min}, 11.2 \mathrm{~J} \mathrm{~cm}^{-2}\right)$. Blue - nuclei, red mitochondria, green - F-actin. Bar represents $50 \mu \mathrm{m}$. 


\section{References}

(1) Novakova, V.; Miletin, M.; Filandrová, T.; Lenčo, J.; Růžička, A.; Zimcik, P. Role of Steric Hindrance in the Newman-Kwart Rearrangement and in the Synthesis and Photophysical Properties of Arylsulfanyl Tetrapyrazinoporphyrazines The Journal of Organic Chemistry 2014, 79, 2082-2093.

(2) Zimcik, P.; Novakova, V.; Kopecky, K.; Miletin, M.; Uslu Kobak, R. Z.; Svandrlikova, E.; Váchová, L.; Lang, K. Magnesium Azaphthalocyanines: An Emerging Family of Excellent Red-Emitting Fluorophores Inorganic Chemistry 2012, 51, 4215-4223.

(3) Kaestner, L.; Cesson, M.; Kassab, K.; Christensen, T.; Edminson, P. D.; Cook, M. J.; Chambrier, I.; Jori, G. Zinc octa-n-alkyl phthalocyanines in photodynamic therapy: photophysical properties, accumulation and apoptosis in cell cultures, studies in erythrocytes and topical application to Balb/c mice skin Photochemical \& Photobiological Sciences 2003, 2, 660-667.

(4) Archer, M. A.; Brechtel, T. M.; Davis, L. E.; Parmar, R. C.; Hasan, M. H.; Tandon, R. Inhibition of endocytic pathways impacts cytomegalovirus maturation Scientific Reports 2017, 7, 46069.

(5) Kirchhausen, T.; Macia, E.; Pelish, H. E. Use of Dynasore, the Small Molecule Inhibitor of Dynamin, in the Regulation of Endocytosis In Methods in Enzymology; Academic Press: 2008; Vol. 438; $p$ 77-93.

(6) Machacek, M.; Kollar, J.; Miletin, M.; Kucera, R.; Kubat, P.; Simunek, T.; Novakova, V.; Zimcik, P. Anionic hexadeca-carboxylate tetrapyrazinoporphyrazine: synthesis and in vitro photodynamic studies of a water-soluble, non-aggregating photosensitizer RSC Advances 2016, 6, 10064-10077.

(7) Choi, C. F.; Tsang, P. T.; Huang, J. D.; Chan, E. Y. M.; Ko, W. H.; Fong, W. P.; Ng, D. K. P. Synthesis and in vitro photodynamic activity of new hexadeca-carboxy phthalocyanines Chemical Communications 2004, 2236-2237.

(8) Liu, W.; Jensen, T. J.; Fronczek, F. R.; Hammer, R. P.; Smith, K. M.; Vicente, M. G. H. Synthesis and Cellular Studies of Nonaggregated Water-Soluble Phthalocyanines Journal of Medicinal Chemistry 2005, 48, 1033-1041.

(9) Oda, K.; Ogura, S.-i.; Okura, I. Preparation of a water-soluble fluorinated zinc phthalocyanine and its effect for photodynamic therapy Journal of Photochemistry and Photobiology B: Biology 2000, $59,20-25$.

(10) Ke, M.-R.; Huang, J.-D.; Weng, S.-M. Comparison between non-peripherally and peripherally tetra-substituted zinc (II) phthalocyanines as photosensitizers: Synthesis, spectroscopic, photochemical and photobiological properties Journal of Photochemistry and Photobiology A: Chemistry 2009, 201, 23-31.

(11) Xia, C.; Wang, Y.; Chen, W.; Yu, W.; Wang, B.; Li, T. New Hydrophilic/Lipophilic Tetra- $\alpha$-(4carboxyphenoxy) Phthalocyanine Zinc-Mediated Photodynamic Therapy Inhibits the Proliferation of Human Hepatocellular Carcinoma Bel-7402 Cells by Triggering Apoptosis and Arresting Cell Cycle Molecules 2011, 16, 1389.

(12) Machacek, M.; Demuth, J.; Cermak, P.; Vavreckova, M.; Hruba, L.; Jedlickova, A.; Kubat, P.; Simunek, T.; Novakova, V.; Zimcik, P. Tetra(3,4-pyrido)porphyrazines Caught in the Cationic Cage: Toward Nanomolar Active Photosensitizers Journal of Medicinal Chemistry 2016, 59, 9443-9456.

(13) Brilkina, A. A.; Dubasova, L. V.; Sergeeva, E. A.; Pospelov, A. J.; Shilyagina, N. Y.; Shakhova, N. M.; Balalaeva, I. V. Photobiological properties of phthalocyanine photosensitizers Photosens, Holosens and Phthalosens: A comparative in vitro analysis Journal of Photochemistry and Photobiology B-Biology 2019, 191, 128-134.

(14) Kollar, J.; Machacek, M.; Jancarova, A.; Kubat, P.; Kucera, R.; Miletin, M.; Novakova, V.; Zimcik, P. Effect of bovine serum albumin on the photodynamic activity of sulfonated tetrapyrazinoporphyrazine Dyes and Pigments 2019, 162, 358-366.

(15) Li, X. S.; Ke, M. R.; Huang, W.; Ye, C. H.; Huang, J. D. A pH-Responsive Layered Double Hydroxide (LDH)-Phthalocyanine Nanohybrid for Efficient Photodynamic Therapy Chemistry-a European Journal 2015, 21, 3310-3317. 
(16) Lan, W. L.; Liu, F. R.; Ke, M. R.; Lo, P. C.; Fong, W. P.; Ng, D. K. P.; Huang, J. D. The effects of formulation and serum albumin on the in vitro photodynamic activity of zinc(II) phthalocyanines substituted with sulfonated quinolineoxy groups Dyes and Pigments 2016, 128, 215-225.

(17) Li, X. S.; Ke, M. R.; Zhang, M. F.; Tang, Q. Q.; Zheng, B. Y.; Huang, J. D. A non-aggregated and tumour-associated macrophage-targeted photosensitiser for photodynamic therapy: a novel zinc(II) phthalocyanine containing octa-sulphonates Chemical Communications 2015, 51, 4704-4707.

(18) Venkatramaiah, N.; Pereira, P. M. R.; Almeida Paz, F. A.; Ribeiro, C. A. F.; Fernandes, R.; Tome, J. P. C. Dual functionality of phosphonic-acid-appended phthalocyanines: inhibitors of urokinase plasminogen activator and anticancer photodynamic agents Chemical Communications 2015, 51, 15550-15553.

(19) Makhseed, S.; Machacek, M.; Alfadly, W.; Tuhl, A.; Vinodh, M.; Simunek, T.; Novakova, V.; Kubat, P.; Rudolf, E.; Zimcik, P. Water-soluble non-aggregating zinc phthalocyanine and in vitro studies for photodynamic therapy Chemical Communications 2013, 49, 11149-11151.

(20) Machacek, M.; Cidlina, A.; Novakova, V.; Svec, J.; Rudolf, E.; Miletin, M.; Kučera, R.; Simunek, T.; Zimcik, P. Far-Red-Absorbing Cationic Phthalocyanine Photosensitizers: Synthesis and Evaluation of the Photodynamic Anticancer Activity and the Mode of Cell Death Induction Journal of Medicinal Chemistry 2015, 58, 1736-1749.

(21) Zimcik, P.; Miletin, M.; Radilova, H.; Novakova, V.; Kopecky, K.; Svec, J.; Rudolf, E. Synthesis, Properties and $<i>$ In Vitro</i> Photodynamic Activity of Water-soluble Azaphthalocyanines and Azanaphthalocyanines Photochemistry and Photobiology 2010, 86, 168-175.

(22) Vachova, L.; Machacek, M.; Kucera, R.; Demuth, J.; Cermak, P.; Kopecky, K.; Miletin, M.; Jedlickova, A.; Simunek, T.; Novakova, V.; Zimcik, P. Heteroatom-substituted tetra(3,4-

pyrido)porphyrazines: a stride toward near- infrared-absorbing macrocycles Organic \& Biomolecular Chemistry 2015, 13, 5608-5612.

(23) Ghazal, B.; Machacek, M.; Shalaby, M. A.; Novakova, V.; Zimcik, P.; Makhseed, S. Phthalocyanines and Tetrapyrazinoporphyrazines with Two Cationic Donuts: High Photodynamic Activity as a Result of Rigid Spatial Arrangement of Peripheral Substituents Journal of Medicinal Chemistry 2017, 60, 6060-6076.

(24) Jiang, X. J.; Yeung, S. L.; Lo, P. C.; Fong, W. P.; Ng, D. K. P. Phthalocyanine -Polyamine Conjugates as Highly Efficient Photosensitizers for Photodynamic Therapy Journal of Medicinal Chemistry 2011, 54, 320-330. 